\title{
An Event-related Potential Study of Selective Auditory Attention in Children and Adults
}

\author{
Donna Coch ${ }^{1}$, Lisa D. Sanders ${ }^{2}$, and Helen J. Neville ${ }^{2}$
}

\begin{abstract}
- In a dichotic listening paradigm, event-related potentials (ERPs) were recorded to linguistic and nonlinguistic probe stimuli embedded in 2 different narrative contexts as they were either attended or unattended. In adults, the typical N1 attention effect was observed for both types of probes: Probes superimposed on the attended narrative elicited an enhanced negativity compared to the same probes when unattended. Overall, this sustained attention effect was greater over medial and left lateral sites, but was more posteriorly distributed and of longer duration for linguistic as compared to nonlinguistic
\end{abstract}

\section{INTRODUCTION}

Over the past few decades, numerous event-related potential (ERP) studies have investigated the human ability to attend selectively to a single sound source (e.g., see Luck, 1998; Woods, 1990; Hillyard \& Picton, 1987; Näätänen, 1982, for reviews). Accumulating evidence suggests that this ability may be the result of both an enhancement of information received from the selected source and a suppression of irrelevant, competing information from other sound sources (Woods, 1990). Overall, auditory attention appears to be deployed as a finely tuned gradient around the attended source (Teder-Sälejärvi, Hillyard, Röder, \& Neville, 1999). Moreover, selective auditory attention can be directed not only to a specific sound source, but to specific features within that sound source, such as frequency or pitch, or to a conjunction of features (Sanders et al., 2001; Woods \& Alain, 1993; Woods, Alho, \& Algazi, 1991). Evidence further suggests that the effects of selective attention can occur relatively early in the processing of auditory information, within primary auditory cortex (Petkov et al., 2004; Hugdahl, Law, et al., 2000; Alho et al., 1999) and within 20 msec of stimulus onset (Woldorff, Hansen, \& Hillyard, 1987), and can last for hundreds of milliseconds (Hansen \& Hillyard, 1980).

Although a number of electrophysiological studies have investigated the exquisite selectivity and sensitivity of sustained auditory attention in adults, very few have

${ }^{1}$ Dartmouth College, ${ }^{2}$ University of Oregon probes. In contrast, in 6- to 8-year-old children the ERPs were morphologically dissimilar to those elicited in adults and children displayed a greater positivity to both types of probe stimuli when embedded in the attended as compared to the unattended narrative. Although both adults and children showed attention effects beginning at about $100 \mathrm{msec}$, only adults displayed left-lateralized attention effects and a distinct, posterior distribution for linguistic probes. These results suggest that the attentional networks indexed by this task continue to develop beyond the age of 8 years.

addressed the development of such attentional systems. The present study was designed to address this gap in knowledge and included adults as well as a group of 6- to 8-year-old children. In a dichotic listening paradigm, ERPs were recorded to linguistic and nonlinguistic probe stimuli embedded in 2 narrative contexts that were either attended or unattended.

\section{Event-related Potential Measures of Selective Auditory Attention in Adults}

In a now classic ERP study of selective auditory attention, Hillyard, Hink, Schwent, and Picton (1973) dichotically presented 2 similar series of tone pips and required participants to attend only to tones played to the designated ear; comparison of the ERP responses to the same tones when attended and unattended revealed an enhanced N1 component to attended tones. A similar N1 attention effect was reported for syllables and environmental sounds (Hink, Hillyard, \& Benson, 1978; Hink, van Voorhis, Hillyard, \& Smith, 1977).

Subsequently, researchers began to report not only an enhanced $\mathrm{N} 1$ for the same stimulus when attended as compared with when unattended but also a later and broader negativity, termed the processing negativity or negative difference ( $N d$ ) wave (Woldorff \& Hillyard, 1991; Hillyard \& Picton, 1987; Hansen, Dickstein, Berka, \& Hillyard, 1983; Hansen \& Hillyard, 1980; Näätänen, 1979, 1982). It was suggested that the $\mathrm{Nd}$ reflected orienting to or further processing of an auditory input deemed relevant in preliminary sensory analyses 
(Näätänen, 1979). Currently, the Nd is thought to consist of both early $\left(\mathrm{Nd}_{\mathrm{e}}\right)$ and late $\left(\mathrm{Nd}_{1}\right)$ components; the early fronto-central component may reflect rapid initial featural analysis of stimuli whereas the late anterior component reflects further processing of the stimuli and maintenance of the attentional trace (e.g., see Woods, 1990; Näätänen, 1982). The $\mathrm{Nd}_{\mathrm{e}}$ is superimposed on the $\mathrm{N} 1$, and there is some evidence that the N1 itself is actually not modulated by attention, as first reported; rather, the effects of the slow wave $\mathrm{Nd}_{\mathrm{e}}$ are simply observed in the typical N1 time window (Woods, 1990; Näätänen, 1982). Other evidence suggests that the N1/M100 (the MEG counterpart to the N100) itself is modulated by attention (e.g., Woldorff et al., 1993).

A small number of studies have attempted to employ a somewhat more ecologically valid design and have investigated selective spatial attention effects in the context of a spoken narrative; in most cases, the typical ERP attention effects have been observed (Trejo, RyanJones, \& Kramer, 1995; Teder, Kujala, \& Näätänen, 1993; Woods, Hillyard, \& Hansen, 1984; Hink \& Hillyard, 1976). For example, irrelevant vowel probes within an attended speech passage elicit more negative ERPs than the same probes in the unattended passage in dichotic presentations (Hink \& Hillyard, 1976). In a more complex design, Woods et al. (1984) presented various speech and tone probe stimuli embedded in dichotically presented prose passages. Speech probes spatially and temporally coincident with the attended passage as compared with the same probes in the unattended passage elicited an enhanced negativity (presumably the $\mathrm{Nd}$ ) beginning at about $50 \mathrm{msec}$ and lasting to $1000 \mathrm{msec}$. In contrast, one type of tone probe elicited an enhanced positivity from 200 to $300 \mathrm{msec}$, most likely an attentional modulation of a different component. The authors suggested that this pattern of results indicated that stimulus selection during linguistic attention might be specifically tuned to speech sounds (Woods et al., 1984).

The possibility of specialized attentional tuning for speech stimuli in the context of spoken word processing raises a related question concerning specialized neural processing for speech in general. In Woods et al.'s (1984) study, the Nd elicited by the CVC speech probe was most prominent over the left hemisphere, whereas effects for other probes evidenced no hemispheric asymmetries. Other ERP selective attention studies have also reported a left-lateralized $\mathrm{Nd}_{1}$ for speech-like (phonemic change) stimuli as compared with nonspeech (intensity change) stimuli (Szymanski, Yund, \& Woods, 1999). In contrast, some studies have reported no asymmetries for either speech or tone stimuli, with each eliciting an Nd similar in morphology and distribution (although longer in latency for more complex speech stimuli; Hansen et al., 1983). Developmental ERP studies have suggested that a left hemisphere specialization for speech either precedes the ability to speak (Molfese, Freeman, \& Palermo, 1975) or be- gins to develop quite early with spoken language experience (Neville \& Bavelier, 2000; Mills, Coffey-Corina, \& Neville, 1993). Studies using fMRI in 3-month-olds (Dehaene-Lambertz, Dehaene, \& Hertz-Pannier, 2002) and optical imaging in newborns (Peña et al., 2003) have reported an early left hemisphere specialization for speech stimuli. Few studies have addressed lateralization in school-age children.

\section{Development of Selective Auditory Attention: Behavioral Evidence}

Behavioral studies have indicated that auditory selective attention skills develop throughout childhood at least until adolescence. Both the abilities to selectively attend to relevant stimuli and to successfully ignore irrelevant stimuli improve progressively with increasing age across childhood (Lane \& Pearson, 1982; Hiscock \& Kinsbourne, 1980; Geffen \& Wale, 1979; Sexton \& Geffen, 1979; Geffen \& Sexton, 1978; Zukier \& Hagen, 1978; Doyle, 1973; Maccoby \& Konrad, 1966). The ability to shift attention quickly and effectively also develops across childhood at least until adolescence (Pearson \& Lane, 1991; Andersson \& Hugdahl, 1987; Hiscock \& Kinsbourne, 1980; Geffen \& Wale, 1979). Further, there is some evidence that background noise creates greater masking effects for younger children as compared with adolescents or adults (Elliott, 1979). In a recent study with children age 6-9 years, alertness and conflict scores evidenced change over time whereas orienting scores did not (Rueda et al., 2004), illustrating that different aspects of attention have different developmental time courses.

Interestingly, there has been some attempt to link sustained selective auditory attention abilities to reading abilities (e.g., Taub, Fine, \& Cherry, 1994). In particular, the ability to make attentional shifts under dichotic listening conditions appears to be related to reading ability (Asbjørnsen \& Bryden, 1998; Hugdahl \& Andersson, 1987). Alternately, some authors have suggested that poorer readers have an attentional capacity limitation but not an inability to focus attention (Dickstein \& Tallal, 1987).

\section{Development of Selective Auditory Attention: Event-related Potential Evidence}

Although behavioral studies offer evidence for the development of selective auditory attention in school-age children, there is very little comparable electrophysiological evidence from children in this age range (e.g., see Ridderinkhof \& van der Stelt, 2000). To the best of our knowledge, there is only one published study of a typical ERP dichotic listening attention paradigm using tones and syllables with young participants (groups with mean age 8.10 years, 14.38 years, and adults; Berman \& Fried- 
man, 1995). Stimuli were presented binaurally over headphones and the expected $\mathrm{Nd}$ was observed in all participants, with $\mathrm{Nd}_{\mathrm{e}}$ amplitude increasing with age, more so for syllables than for tones, and $\mathrm{Nd}_{\mathrm{e}}$ distribution more posterior in adults than in children. For all age groups, the $\mathrm{Nd}$ attention effect for syllables was smaller and later than that for tones. The primary effect of age appeared to be smaller negative ERPs elicited by stimuli in the unattended channel, which the authors suggested might reflect a narrowing of attentional focus or greater facility in suppressing unattended inputs with age (Berman \& Friedman, 1995).

In a series of cross-sectional studies with male children investigating ERP correlates of attention deficit/ hyperactivity disorder, Satterfield and colleagues reported that attention elicited the typical enhanced negativity in normal control boys aged $6-8$ years in a cross-modal auditory/visual selective attention paradigm (e.g., Satterfield, Schell, \& Nicholas, 1994; Satterfield, Schell, Nicholas, \& Backs, 1988). However, in a longitudinal study, they reported that the central $\mathrm{Nd}_{\mathrm{e}}$ was absent in 6-year-olds, but peaked at about $250 \mathrm{msec}$ when the same children were tested 2 years later at age 8 years; the frontal $\mathrm{Nd}_{1}$ shortened in latency from age 6 to age 8 years (Satterfield, Schell, Nicholas, Satterfield, \& Freese, 1990). In a more typical selective auditory attention paradigm, the expected $\mathrm{N} 1$ attention effect was observed in adolescents aged 12-14 years (Loiselle, Stamm, Maitinsky, \& Whipple, 1980). Other studies have reported similar attention effects in adolescent boys (Lovrich \& Stamm, 1983; Zambelli, Stamm, Maitinsky, \& Loiselle, 1977).

\section{The Present Study}

There is clearly a lack of ERP investigations of the development of selective auditory attention effects across the early school-age years. Behavioral evidence unequivocally indicates that selective attention abilities are developing across childhood and into adolescence. In the present study, we employed ERPs and a complex dichotic listening task modeled after that used by Woods et al. (1984) to study the development of the neural systems important for sustained auditory attention. Children and adults were asked to listen to 1 of 2 concurrently presented narratives as it periodically switched between a speaker at their right and a speaker at their left (as the other narrative played from the opposite speaker). ERPs were recorded to linguistic (a token of the syllable $\mid b a /$ ) and nonlinguistic (a buzz) probe stimuli embedded in the attended and unattended narratives. Comparisons of the ERPs elicited by the same probe stimuli when played from the attended and unattended source indexed ERP attention effects. Comparisons of responses to linguistic and nonlinguistic probes were employed to index the degree of separability of the neural systems processing the different types of stimuli including any left hemisphere specialization for speech stimuli in the context of the ongoing narrative. Comparisons between children and adults revealed the developmental time course of ERP indices of selective auditory spatial attention. Given the evidence reviewed above, we hypothesized typical N1/Nd effects, perhaps differently distributed, in children and adults; distinct responses for linguistic and nonlinguistic probes with evidence for left hemisphere specialization for linguistic processing, particularly in adults; and evidence of development of the ERP waveform between adults and 6- to 8-year-old children.

\section{RESULTS \\ Behavioral Testing Results}

All scores on the standardized behavioral tests administered to children were within normal limits. PPVT (Dunn \& Dunn, 1997) standard scores ranged from 103 to 139, with an average of $118.8 \pm 9.8$; corresponding percentile rank scores ranged from 58 to 99.5. Standard scores on the Word Identification subtest of the WRMT (Woodcock, 1987) ranged from 94 to 145, with an average of $113.4 \pm 14.3$. Standard scores on the Word Attack subtest of the WRMT ranged from 81 to 145, with an average of $115.8 \pm 15.3$.

\section{Behavioral Event-related Potential Results}

Only participants who answered at least 8 out of 10 posttest comprehension questions correctly were included in analyses. Children answered an average of $9.4 \pm 0.8$ questions correctly, whereas adults answered an average of $9.8 \pm 0.4$ questions correctly. This difference between groups was significant $[t(42)=2.5$, $p<.05]$.

\section{Event-related Potential Results}

Adults

Component analyses (see Table 1). The probes embedded in both the attended and unattended stories elicited typical early auditory ERP components in adults: a positivity between 50 and $150 \mathrm{msec}$ (P1), a negativity between 100 and $200 \mathrm{msec}$ (N1), and a subsequent positivity between 200 and $400 \mathrm{msec}$ (P2). Across probe type, the P1 was largest at medial and anterior electrode sites [laterality, $F(1,21)=126.12$, $p<.001$; anterior/posterior, $F(5,105)=36.27, p<.001$; Laterality $\times$ Anterior/Posterior, $F(5,105)=34.32$, $p<.001]$. The $\mathrm{P} 1$ peaked slightly earlier for linguistic probes (mean latency $=98 \mathrm{msec}$ ) than for nonlinguistic probes (mean latency $=103 \mathrm{msec}$ ), $F(1,21)=5.42$, $p<.05$. 
Table 1. Adults: Component Analyses

P1 N1

P2

(50-150 msec) (100-200 msec) (200-400 msec)

\begin{tabular}{lccc}
\hline $\begin{array}{c}\text { Amplitude } \\
(\mu \mathrm{V})\end{array}$ & $1.50(0.12)$ & $-2.34(0.15)^{\mathrm{a}}$ & $1.27(0.11)$ \\
$\begin{array}{c}\text { Nonlinguistic } \\
\text { probes }\end{array}$ & $1.61(0.14)$ & $-2.13(0.15)^{\mathrm{a}}$ & $1.53(0.15)$ \\
$\begin{array}{c}\text { Linguistic } \\
\text { probes }\end{array}$ & $1.39(0.13)$ & $-2.55(0.17)^{\mathrm{a}}$ & $1.02(0.11)$ \\
$\begin{array}{c}\text { Latency } \\
\left(\begin{array}{l}\text { msec }) \\
\text { Nonlinguistic } \\
\text { probes }\end{array}\right.\end{array}$ & $103(1.9)$ & $176(3.1)$ & $279(5.4)$ \\
$\begin{array}{c}\text { Linguistic } \\
\text { probes }\end{array}$ & $98(2.0)$ & $195(3.6)$ & $304(5.8)$ \\
\hline
\end{tabular}

Peak amplitude and latency measured across all sites. Standard error in parentheses.

${ }^{\text {a}}$ Peak-to-peak amplitude (see Methods for details).

Analysis of the peak-to-peak amplitude between P1 and $\mathrm{N} 1$ revealed that the $\mathrm{N} 1$ component, like the $\mathrm{P} 1$, was largest over medial and anterior electrode sites [laterality, $F(1,21)=116.77, p<.001$; Laterality $\times$ Anterior/ Posterior, $F(5,105)=24.77, p<.001]$. Unlike the P1, the N1 peaked significantly earlier for nonlinguistic probes (mean latency $=176 \mathrm{msec}$ ) than for linguistic probes $($ mean latency $=195 \mathrm{msec}), F(1,21)=25.29, p<.001$. The N1 was also larger in amplitude for linguistic than nonlinguistic probes (see Figure 1), $F(1,21)=19.69$, $p<.001$. Overall, the N1 component was larger to probes played within the attended story than to probes played within the unattended story, $F(1,21)=5.62$, $p<.05$.

The second positivity elicited by the probes, P2, was larger over the right hemisphere, $F(1,21)=5.90, p<.05$, and at medial, $F(1,21)=21.02, p<.001$, and anterior, $F(5,105)=8.50, p<.001$ sites. The $\mathrm{P} 2$ elicited by nonlinguistic probes was larger, $F(1,21)=11.31$, $p<.01$, and earlier (mean latency $=279 \mathrm{msec}$ ), $F(1,21)=11.68, p<.01$, than the $\mathrm{P} 2$ to linguistic probes (mean latency $=304 \mathrm{msec}$ ). Across probe type, the P2 peaked earlier at medial sites for probes played within the attended story than those played within the unattended story [Attention $\times$ Laterality, $F(1,21)=4.71$, $p<.05]$. Overall, across probe type, the amplitude of P2 was not modulated by attention $(p=.947)$.

Attention effects: Nonlinguistic probes. Within the 100to 175-msec epoch, nonlinguistic probes elicited larger negativities when played from the attended speaker than from the unattended speaker (see Figure 1A),
$F(1,21)=5.69, p<.05$. Like the $\mathrm{N} 1$ component itself, this attention effect was largest over medial and anterior electrode sites [Attention $\times$ Laterality, $F(1,21)=7.82$, $p<.05$; Attention $\times$ Laterality $\times$ Anterior/Posterior, $F(5,105)=4.25, p<.001]$. Analyses of consecutive 25 -msec bins between 0 and $300 \mathrm{msec}$ revealed that this $\mathrm{N} 1$ attention effect began within the $100-$ to $125-\mathrm{msec}$ epoch.

Attention effects: Linguistic probes. Within the 100- to 250-msec epoch, linguistic probes elicited larger negativities when played from the attended speaker than from the unattended speaker (see Figure 1B), $F(1,21)=5.00, p<.05$. This attention effect was largest over medial and posterior electrode sites [Attention $\times$ Laterality, $F(1,21)=10.31, p<.01$; Attention $\times$ Anterior/Posterior, $F(5,105)=3.57, p<.05$; Attention $\times$ Laterality $\times$ Anterior/Posterior, $F(5,105)=$ $3.60, p<.05]$. In 25 -msec bin analyses, this attention effect was also shown to begin within the 100- to 125-msec epoch.

Woods et al. (1984) reported that the N1 attention effect was sensitive to frequency, raising the possibility that the N1 attention effect to linguistic probes observed here may have been influenced by voice-specific acoustic differences between the probe and the stories read by a man and a woman. In a follow-up analysis, we measured the pitch from 30 random 100-msec intervals from each story recording (mean \pm SE pitch: male, $150 \pm 10.1 \mathrm{~Hz}$; female, $212 \pm 8.2 \mathrm{~Hz}$ ) and then subtracted from these measurements the mean pitch of the linguistic probe $(158 \mathrm{~Hz})$. An independent samples $t$ test on the absolute value of the pitch difference for the 2 stories indicated a trend for difference $[t(58)=$ $1.96, p=.06]$, suggesting that voice-specific differences based on the acoustics (in terms of pitch) may have played some role in, but were probably not a major contributing factor to, the observed effects. Teder et al. (1993) also reported no effect of male or female voice on the attention effect.

Comparison of probe types. Overall, across probe types, a classic attention effect began around $100 \mathrm{msec}$ such that probes played from the attended speaker elicited larger negativities than the same probes played from the unattended speaker (see Figure 1 and Table 2), $F(1,21)=11.14, p<.01$. This attention effect was largest over medial sites [Attention $\times$ Laterality, $F(1,21)=$ 21.21, $p<.001]$ and extended to left lateral sites [Attention $\times$ Laterality $\times$ Hemisphere, $F(1,21)=9.22$, $p<.01]$ for both types of probes (Probe Type $\times$ Attention $\times$ Laterality $\times$ Hemisphere, $p=.971)$. However, for linguistic probes as compared with nonlinguistic probes, this attention effect had a more posterior distribution [Attention $\times$ Probe Type $\times$ Anterior/Posterior, $F(5,105)=6.70, p<.01]$ and 


\section{A Nonlinguistic Attention Probe}

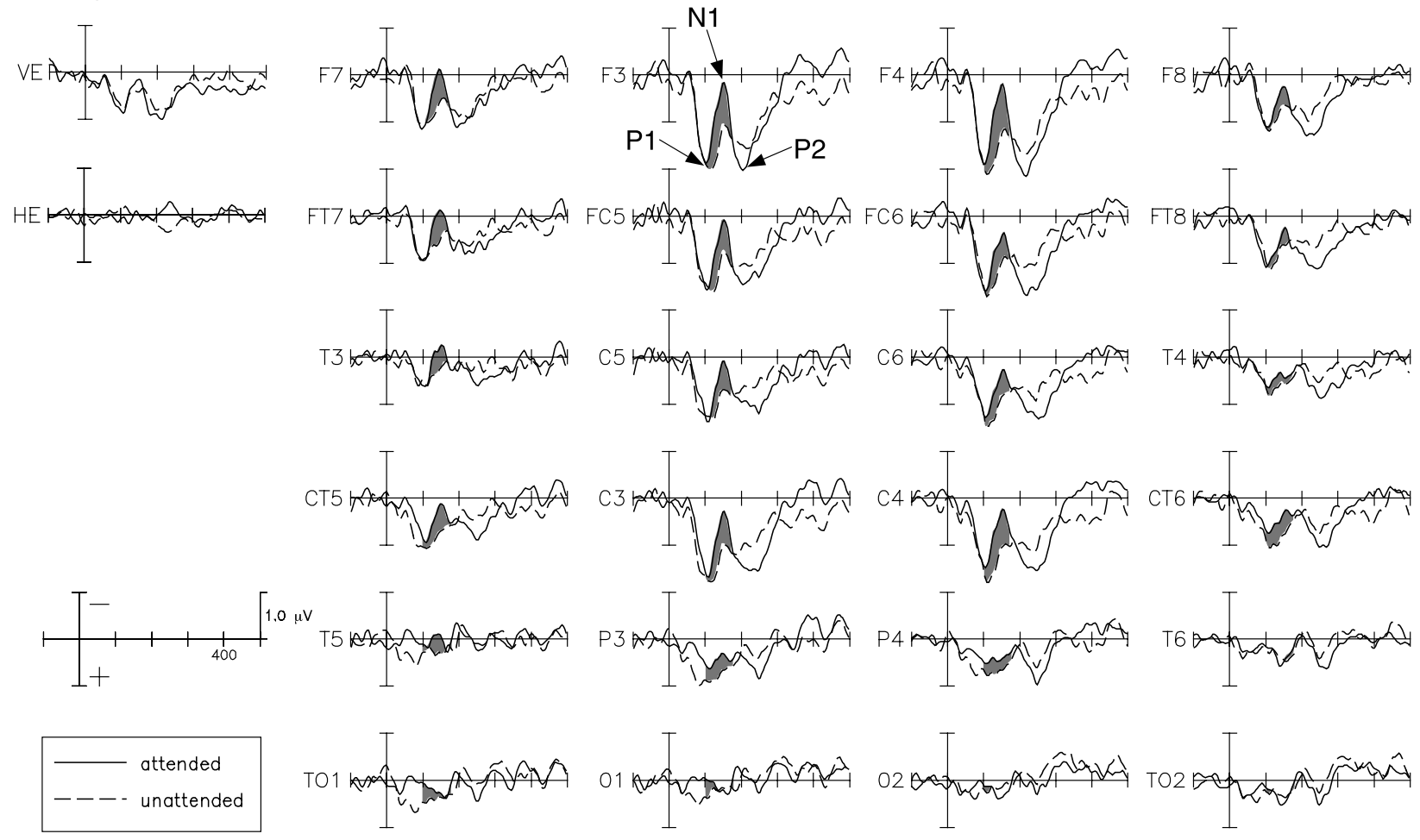

\section{B Linguistic Attention Probe}

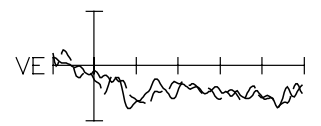

F7)
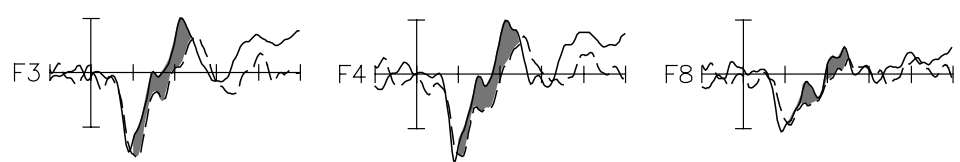

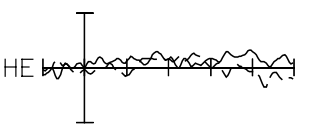
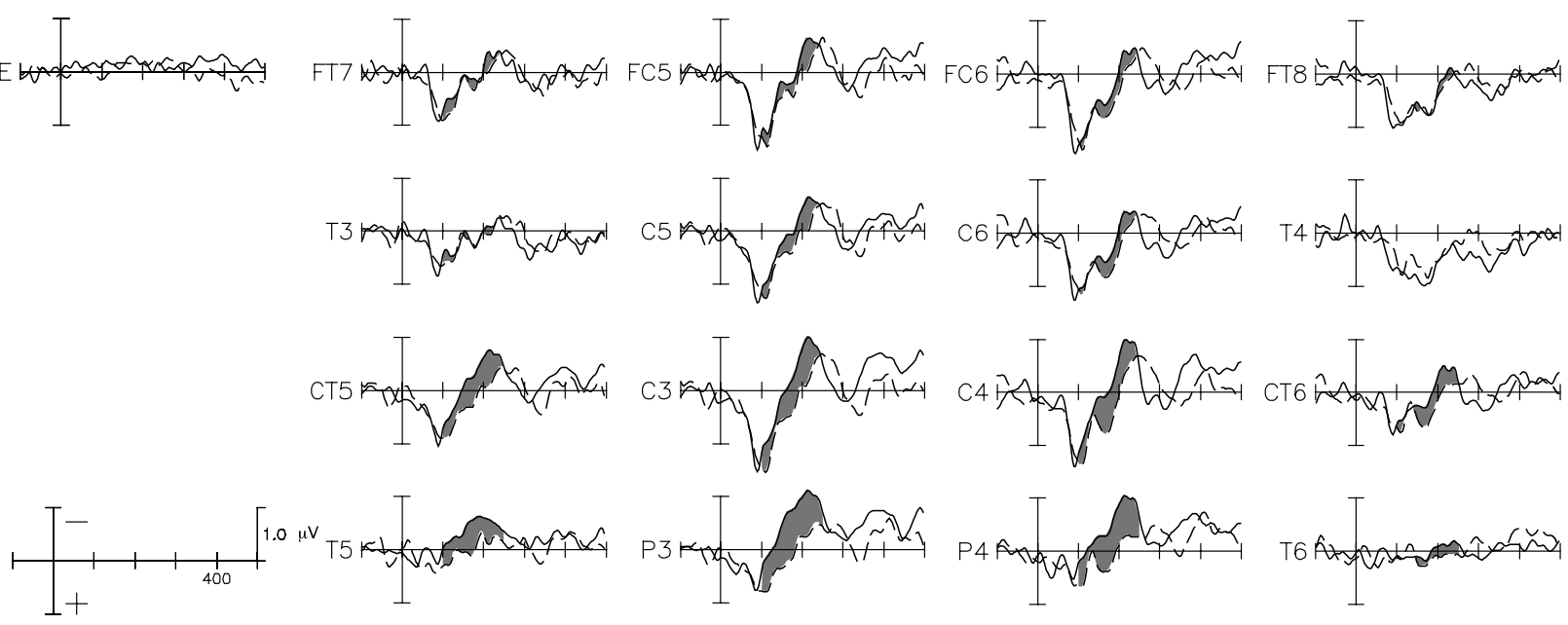

$1.0 \mathrm{v}$ (5)
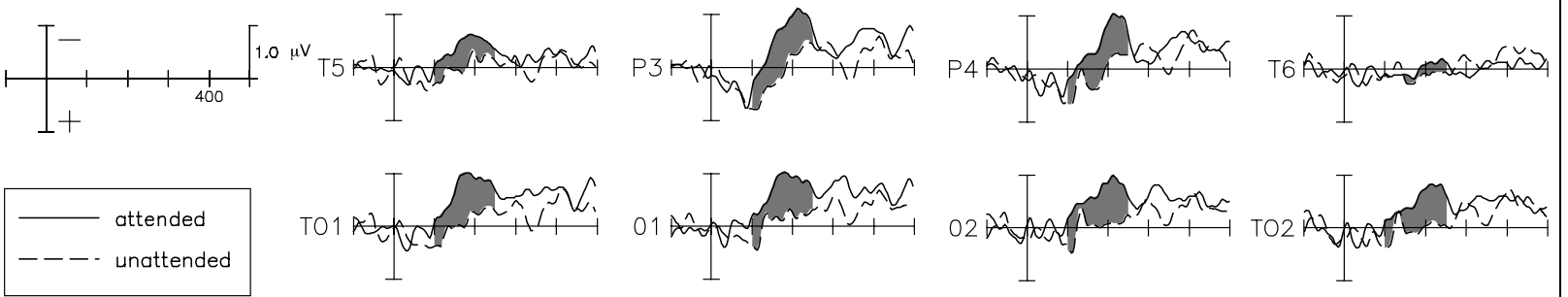

Figure 1. In adults, the typical sequence of P1-N1-P2 components was observed for both types of probe stimuli, with each component largest at medial anterior sites. Each component of interest is identified at site F3. Classic attention effects (probes played from the attended speaker elicited larger negativities than the same probes played from the unattended speaker) were evident for (A) nonlinguistic probes at medial and anterior sites from 100 to $175 \mathrm{msec}$ and (B) linguistic probes at medial and posterior sites from 100 to 250 msec. More anterior sites are toward the top, more posterior sites are toward the bottom; left hemisphere sites are on the left, right hemisphere sites are on the right; medial sites are toward the middle of the figure, lateral sites are toward the edges of the figure; and negative is "plotted up." 
Table 2. Adults: Attention Effects

N1 N1 P2

(100-175 $\mathrm{msec})(100-250 \mathrm{msec})(175-250 \mathrm{msec})$

$\begin{array}{llll}\begin{array}{c}\text { Nonlinguistic } \\ \text { probes }\end{array} & & & \\ \text { Attended } & 0.50(0.14) & - & 0.71(0.13) \\ \text { Unattended } & 0.79(0.15) & - & 0.53(0.13)\end{array}$

Linguistic

probes

$\begin{array}{llll}\text { Attended } & - & -0.11(0.17) & -0.43(0.20)\end{array}$

Unattended

$0.22(0.14) \quad-0.05(0.15)$

Mean amplitude measured across all sites. Standard error in parentheses.

extended into a later time window [mean amplitude within the 175- to 250-msec epoch: Attention $\times$ Probe type, $F(1,21)=12.02, p<.01$; for linguistic probes, $F(1,21)=4.59, p<.05$; for nonlinguistic probes, $p=.119]$. Thus, in the later time window in adults, the increased negativity with attention was observed only for linguistic probes.

\section{Children}

Component analyses (see Table 3). The morphology of the ERP waveforms in children was dissimilar to that observed in adults. Instead of the distinct positivenegative-positive sequence seen in adults, ERPs in children consisted of a single broad, sustained positivity that began around $100 \mathrm{msec}$ and continued until at least $300 \mathrm{msec}$ after stimulus onset. In mean amplitude measurements, this positive component was largest over medial and anterior sites (see Figure 2) [laterality, $F(1,21)=106.51, p<.001$; anterior/posterior $F(1,21)=51.03, p<.001]$. Across probe type, measured at the 4 most anterior rows of electrodes, the amplitude of this component was significantly enhanced with attention $[F(1,21)=10.06, p<.005]$.

Attention effects: Nonlinguistic probes. Within the 100- to 250-msec epoch, nonlinguistic probes elicited a greater positivity at anterior electrode sites when played from the attended speaker (see Figure 2A) [Attention $\times$ Anterior/Posterior, $F(5,105)=6.34, p<.001$; attention at anterior 4 rows, $F(1,21)=8.49, p<.01]$. In 25 -msec bin analyses, this attention effect was shown to begin within the 100- to 125 -msec epoch, as observed in adults.

Attention effects: Linguistic probes. Within the 100- to 250-msec epoch, linguistic probes likewise elicited a greater positivity at anterior electrode sites when played from the attended speaker (see Figure 2B) [Attention $\times$ Anterior/Posterior, $F(5,105)=8.21, p<.001$; attention at anterior 4 rows, $F(1,21)=6.67, p<.05]$. As with the attention effect for nonlinguistic probes, this positive difference began within the 100- to 125 -msec epoch in 25-msec bin analyses.

\section{Comparison of probe types}

Overall, across probe type, an attention effect began at about $100 \mathrm{msec}$, such that probes played from the attended speaker tended to elicit larger positivities than the same probes played from the unattended speaker $[F(1,21)=3.68, p=.069]$. Across probe type, this effect was largest at anterior sites [Attention $\times$ Anterior/Posterior, $F(5,105)=11.53, p<.001]$. There were no significant differences in the amplitudes, onset latencies, or distributions of the attention effects for the linguistic and nonlinguistic probe stimuli in children.

\section{Comparison of Adults and Children}

Difference measurements (attended-unattended) were normalized to allow for comparison of the distribution of attention effects across groups. Analyses of normalized data revealed a significant Group $\times$ Hemisphere $\times$ Laterality interaction $[F(1,42)=11.68, p<.001]$ consistent with the left lateral extension (or relatively greater left-than-right lateral extension) of attention effects observed in adults but not in children (see Figure 3). Analyses of normalized data also revealed a Group $\times$ Probe Type $\times$ Anterior/Posterior interaction

Table 3. Children: Component Analyses and Attention Effect

\begin{tabular}{lc}
\hline & Positivity $(100-250$ msec $)$ \\
\hline Amplitude $(\mu V)$ & $1.78(0.16)$ \\
Nonlinguistic probes & $1.98(0.33)$ \\
Linguistic probes & $1.60(0.30)$ \\
& \\
Nonlinguistic probes & $2.58(0.34)$ \\
Attended & $3.06(0.34)$ \\
Unattended & $2.10(0.34)$ \\
& \\
Linguistic probes & $2.22(0.29)$ \\
Attended & $2.65(0.27)$ \\
Unattended & $1.79(0.31)$ \\
\hline
\end{tabular}

Mean amplitude measured across all sites for overall amplitude; mean amplitude measured at 4 most anterior rows for attention effect. Standard error in parentheses. 
A Nonlinguistic Attention Probe
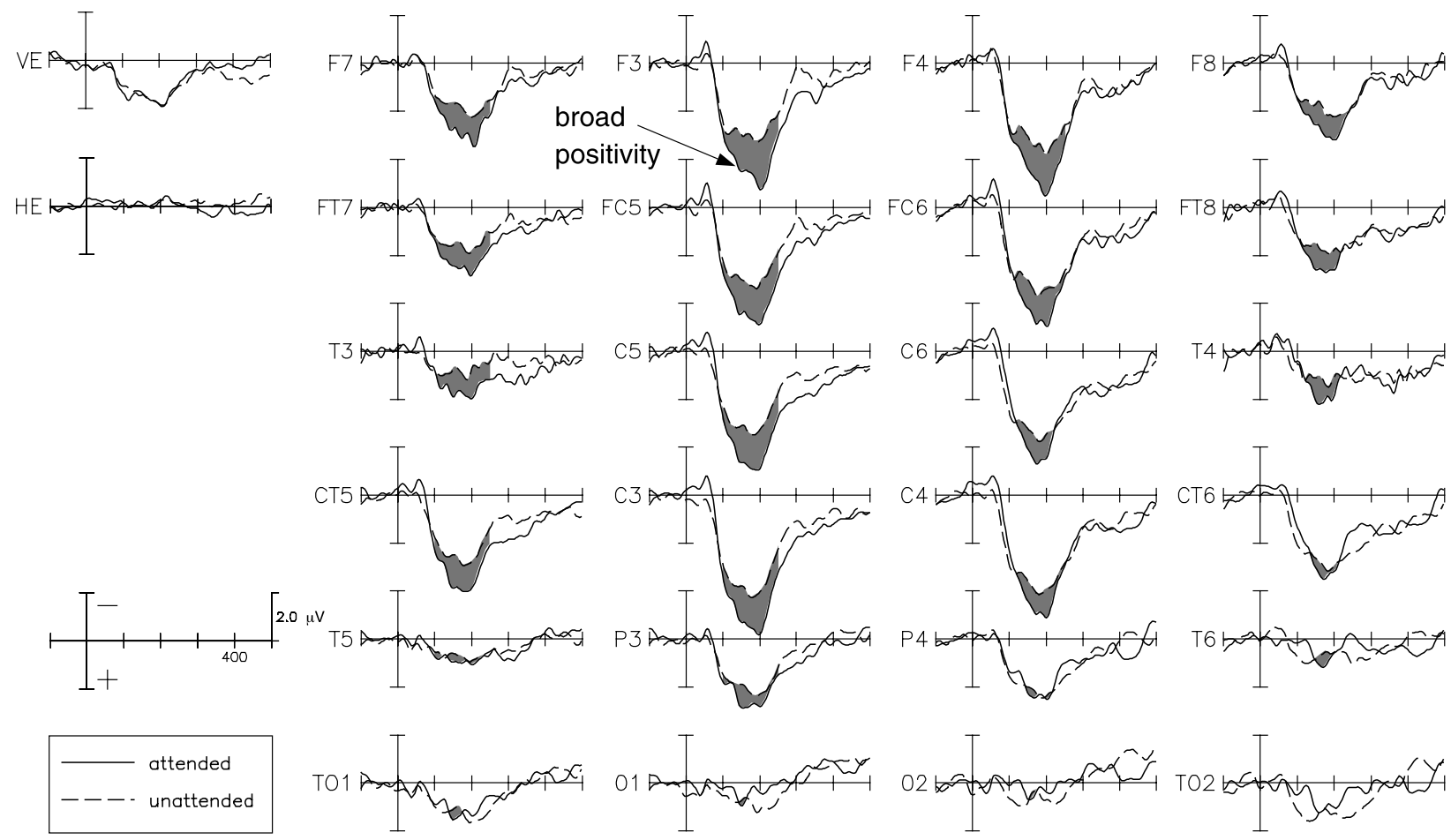

T02 waty

B Linguistic Attention Probe
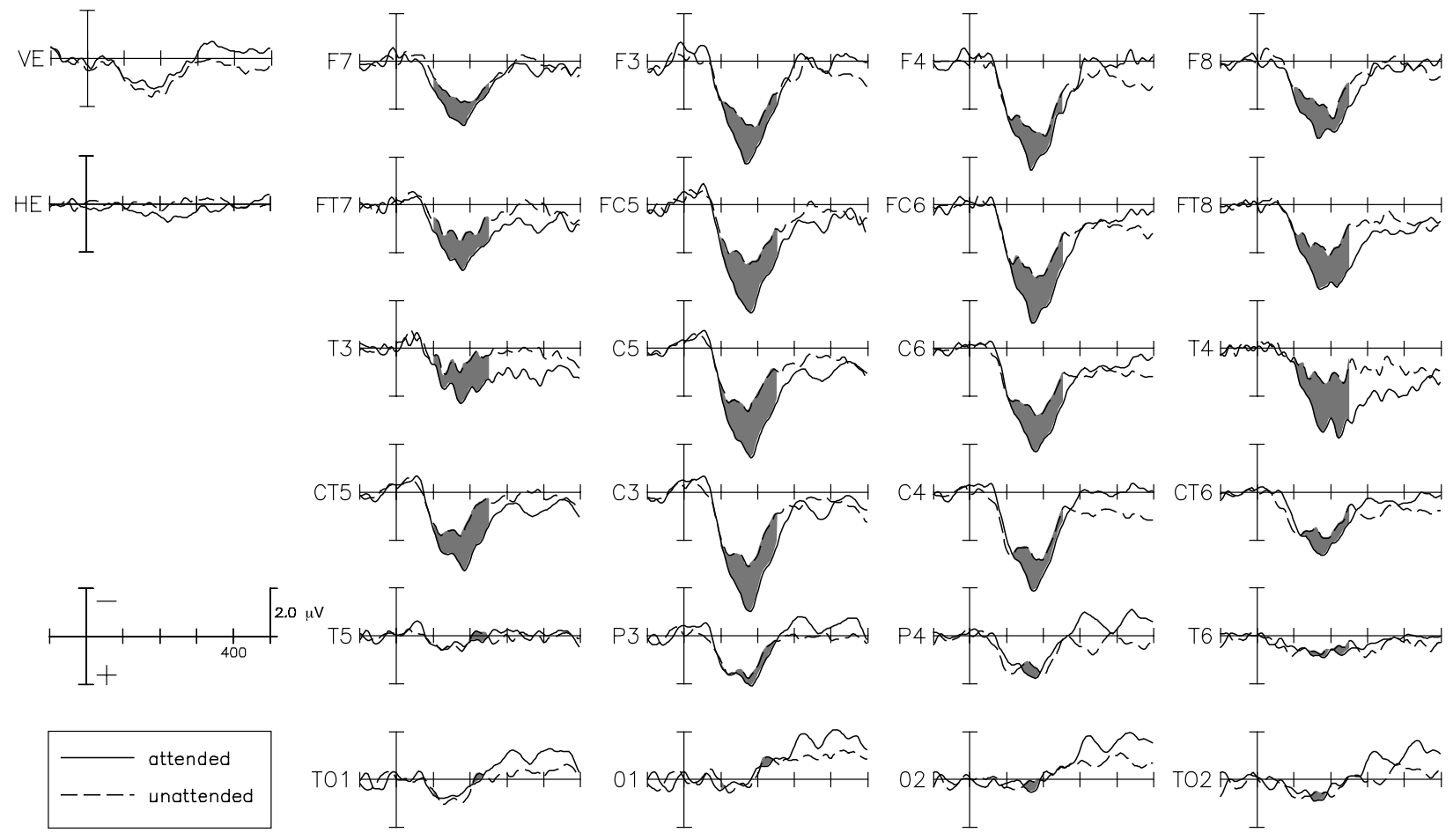

Figure 2. In children, instead of the typical P1-N1-P2 series, a single sustained broad positivity largest at medial and anterior sites characterized the ERPs elicited by both types of probe stimuli. An attention effect (probes played from the attended speaker elicited a larger positivity than the same probes played from the unattended speaker) with similar medial anterior distribution was evident for (A) nonlinguistic probes beginning at 100-125 msec and (B) linguistic probes beginning at 100-125 msec. All else (although note scale) as in Figure 1. 

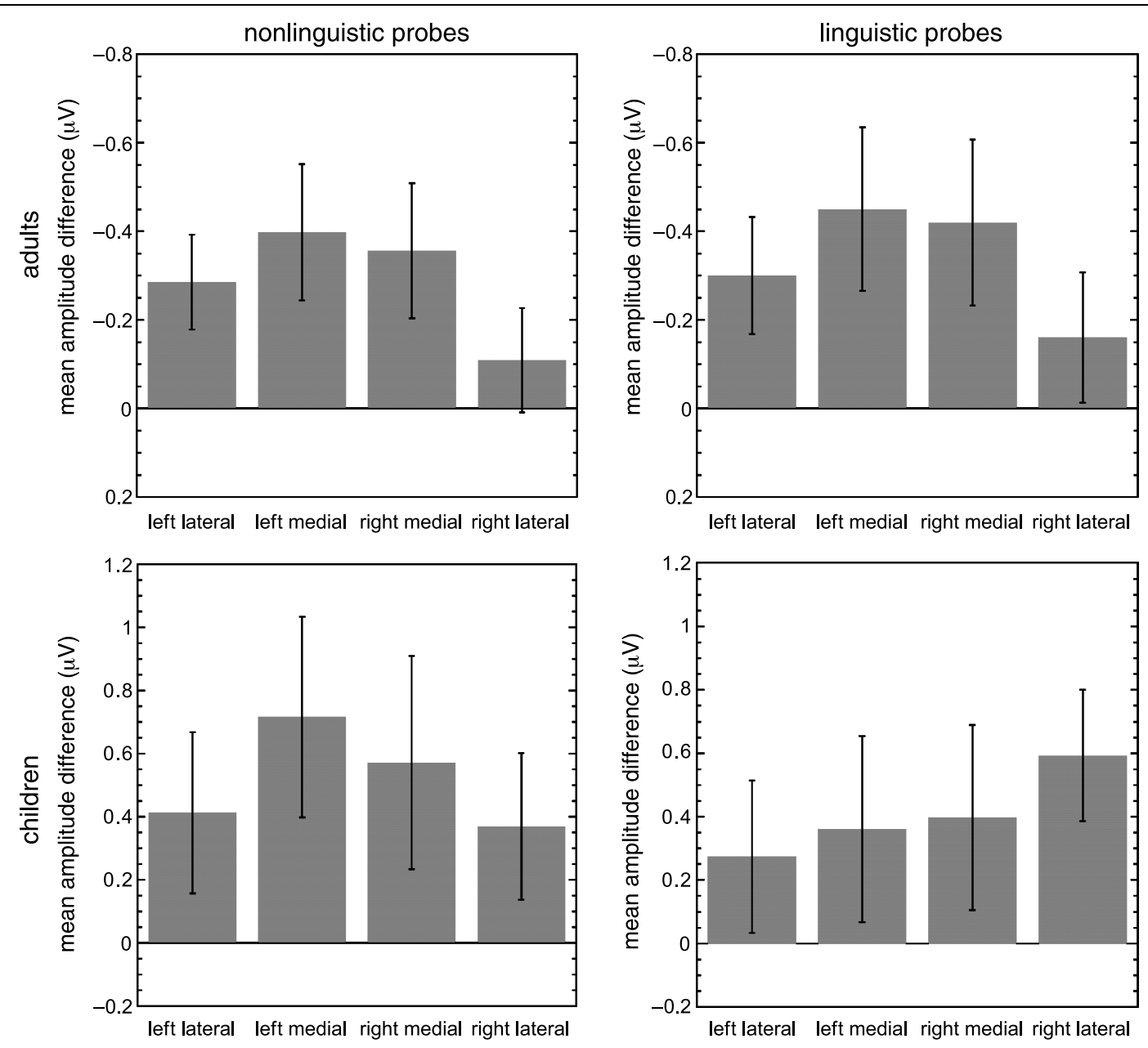

Figure 3. In a comparison of the attention effects (attended-unattended) in children and adults using normalized difference measures, a Group $\times$ Hemisphere $\times$ Laterality interaction reflected the relatively greater left-than-right lateral extension of attention effects observed in adults.

$[F(5,210)=3.26, p=.054]$ reflecting the distinct distributions of attention effects for linguistic (more posterior) and nonlinguistic (more anterior) probes in adults and the similarity of the distribution of these effects in children (see Figure 4). Moreover, this interaction indexes the fact that adults and children showed more similarly distributed attention effects for nonlinguistic probes (nonlinguistic probes: all ps $>.35$ ), whereas adults evidenced a more posteriorly distributed attention effect for linguistic probes [linguistic probes: Group $\times$ Anterior/Posterior, $F(5,210)=9.24$, $p<.001]$.

\section{Correlations between Event-related Potential and Behavioral Measures in Children (Only)}

A difference measure of mean amplitude of ERPs elicited by attended and unattended probes at sites FC5 and FC6 was not correlated with any of our behavioral measures of reading skill in the children (all $p s>.45$ ). Further, there were no significant correlations between children's age and any measure of reading skill or this ERP measure of selective auditory attention (all ps $>.24)$.

\section{DISCUSSION}

Children and adults attended to one narrative as it periodically switched from a speaker at their right to a speaker at their left while another narrative played from the opposite speaker. Simultaneously, ERPs were recorded to linguistic and nonlinguistic probe stimuli superimposed on the narratives at both the attended and unattended speakers. Consistent with previous findings (Woldorff \& Hillyard, 1991; Hillyard \& Picton, 1987; Woods et al., 1984; Hansen, Dickstein, et al., 1983; Hansen \& Hillyard, 1980; Näätänen, 1979, 1982; Hink et al., 1977, 1978; Hillyard et al., 1973), in adults, the ERP waveforms evidenced the typical auditory attention effect for both types of probes: an enhanced negativity for probes when attended as compared with those same 

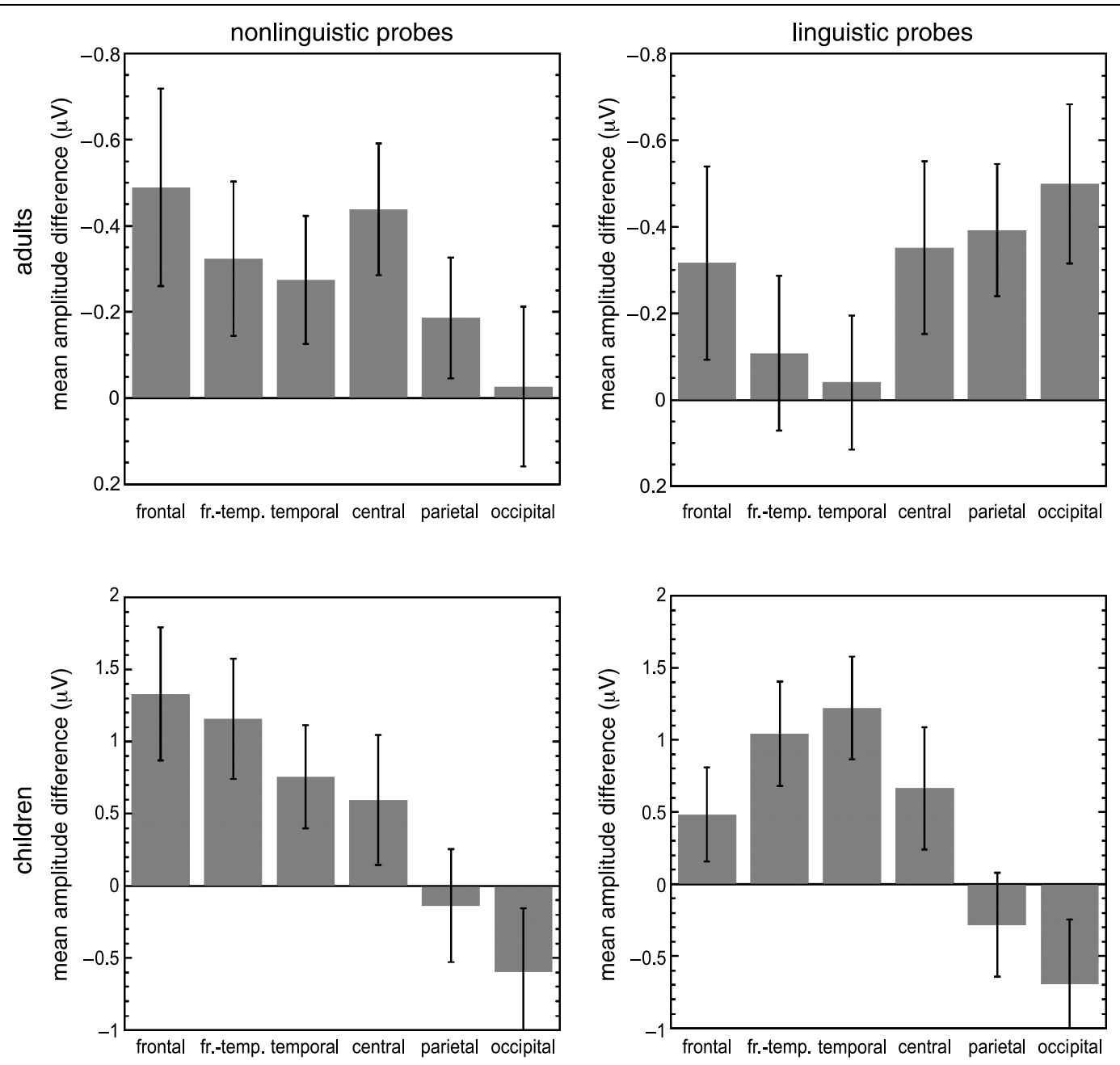

Figure 4. In a comparison of the attention effects (attended-unattended) in children and adults using normalized difference measures, a Group $\times$ Probe Type $\times$ Anterior/Posterior interaction reflected the distinct anterior/posterior distributions of the attention effects to linguistic and nonlinguistic probes in adults in comparison to the relatively similar distributions in children. Further, this result highlights the similarity of the anterior/posterior distribution of the attention effects to nonlinguistic probes in children and adults and the unique posterior distribution of the attention effect for linguistic probes in adults.

probes when unattended. This effect was longer lasting and more posteriorly distributed for linguistic than nonlinguistic probes. In contrast, the ERP waveforms of children were morphologically dissimilar to those of adults and evidenced a greater broad positivity to both types of probe stimuli when attended as compared with unattended. This attention effect had a similar, anterior distribution for the 2 probe types. Remarkably, both the typical attention effect involving an enhanced negativity in adults and the atypical attention effect involving an enhanced positivity in children onset at about 100 msec.

\section{Adults}

Adults evidenced the typical auditory ERP waveform morphology including P1, N1, and P2 components greatest at medial and anterior sites, with both the linguistic and nonlinguistic probe stimuli eliciting each of these components. Absent attention effects, linguistic probes elicited an earlier P1, later and larger N1, and later and smaller P2 than nonlinguistic probes. Differential processing of the 2 types of probes suggests that these early components may be sensitive to more than just the fine acoustic characteristics of auditory stimuli. The probe stimuli were matched in terms of acoustic primitives including spectral frequency, but the later and larger N1 to linguistic probes in particular suggests that the linguistic nature of these probes did affect early processing in the context of the language-based task.

Considering the effects of attention directly, adults evidenced the typical $\mathrm{N} 1$ or $\mathrm{Nd}$ attention effect for both linguistic and nonlinguistic probes such that probes played from the attended speaker elicited more negative ERPs than the same probes played from the unattended speaker. This effect was greater over medial sites and 
lateral sites of the left hemisphere across probe type. Some authors have reported a more left-lateralized $\mathrm{Nd}$ for linguistic as compared with nonlinguistic stimuli (Szymanski et al., 1999; Woods et al., 1984), whereas others have not (Hansen, Dickstein, et al., 1983). The present pattern of lateral left hemisphere asymmetry suggests that the context of the linguistic task-listening selectively to one narrative-may have influenced the lateralized processing of all stimuli within the "spotlight" of linguistic attention; results of MEG, PET, and fMRI studies have indicated left hemisphere specialization for many aspects of speech processing (e.g., Poldrack et al., 2001; Shtyrov, Kujala, Palva, Ilmoniemi, \& Näätänen, 2000; Hugdahl, Brønnick, et al., 1999; Zatorre, Evans, Meyer, \& Gjedde, 1992). Other aspects of speech processing, such as voicing contrasts, have been reported to be more dependent on the right hemisphere in both adults and children (Simos, Molfese, \& Brenden, 1997; Segalowitz \& Cohen, 1989; Molfese \& Molfese, 1988).

Although the hemispheric distribution of attention effects for the probe types was similar, the anterior/ posterior distribution was not. Linguistic probes clearly elicited more posteriorly distributed processing than nonlinguistic probes in adults. Considering the limited spatial resolution of the ERP technique, it is difficult to draw conclusions regarding this observed pattern. However, it is interesting to speculate on a possible connection to specialized linguistic processing within posterior language areas. Regardless, the differential distribution of effects along the anterior/posterior dimension in adults indicates that linguistic and nonlinguistic probe stimuli were distinguished within the spatial, linguistic attentional spotlight.

The high temporal resolution of the ERP technique revealed further evidence for differential processing of the probe stimuli in adults: The duration of the attention effect to linguistic probes extended beyond that for nonlinguistic probes. Woods et al. (1984) have suggested that stimulus selection during linguistic attention may be specifically tuned to speech sounds, which may be reflected here in the temporally extended effect only for linguistic probes. Although it is possible that this result reflects further processing and maintenance of the attentional trace in terms of the $\mathrm{Nd}_{1}$ (e.g., see Woods, 1990; Näätänen, 1982), the typical $\mathrm{Nd}_{1}$ is maximal at anterior sites, whereas the present effect (not distinguishing between early and late $\mathrm{Nd}$ ) has a posterior distribution. It is interesting to speculate that within the linguistic context of the task, only the linguistic probe stimuli were subject to further analysis precisely because of their potentially relevant (i.e., linguistic and possible semantic) nature, whereas early analysis of the nonlinguistic probes was sufficient to gate them from further processing. If this is the case, it would suggest that spatial linguistic attention can be remarkably precise, as the linguistic and nonlinguistic stimuli were spectrally matched. This would be consistent with other studies demonstrating the precision of selective auditory attention outside the linguistic domain (Sanders et al., 2001; Woods \& Alain, 1993; Woods et al., 1991).

\section{Children}

In contrast to adults, children did not evidence typical auditory ERP waveforms. Instead of the common P1N1-P2 sequence, the ERPs of children were characterized by a single sustained positivity largest at medial and anterior sites that began at about $100 \mathrm{msec}$ and extended to at least $300 \mathrm{msec}$. Linguistic and nonlinguistic probe stimuli elicited similarly distributed positivities.

For the most part, developmental ERP studies tend to report similar componentry in children and adults (e.g., Davis, Bruce, Snyder, \& Nelson, 2003; Coch, Grossi, Coffey-Corina, Holcomb, \& Neville, 2002; Oades, Dittmann-Balcar, \& Zerbin, 1997; Thomas \& Nelson, 1996). However, the N1 is not a unitary event and likely has multiple underlying sources (Näätänen \& Picton, 1987), each of which may have a different developmental time course (e.g., Takeshita et al., 2002), and each of which may be differently affected by task parameters. Multiple developmental studies, typically using an auditory oddball paradigm, have reported changes in N1 amplitude, latency, and distribution across childhood; the general pattern of results indicates a smaller, later, and more posteriorly distributed $\mathrm{N} 1$ in children as compared with adults (Albrecht, Suchodoletz, \& Uwer, 2000; Pang \& Taylor, 2000; Ponton, Eggermont, Kwong, \& Don, 2000; Bruneau, Roux, Guérin, Barthélémy, \& Lelord, 1997; Oades et al., 1997; Tonnquist-Uhlén, Borg, \& Spens, 1995; Fuchigami et al., 1993; Martin, Barajas, Fernandez, \& Torres, 1988; Goodin, Squires, Henderson, \& Starr, 1978). Moreover, in the waveforms of children younger than age 7-9 years, it has been reported that the $\mathrm{N} 1$ is sometimes "unreliable" or difficult to identify (Ponton et al., 2000; Bruneau et al., 1997; Martin et al., 1988; Daruna \& Rau, 1987), perhaps because the generators are not present or are not optimally oriented (Bruneau et al., 1997, p. 36).

Indeed, a number of previous reports in the literature have documented that the auditory ERP componentry typical in adults is not always observed in young children; in fact, there is some consistency across studies in reporting an early positivity peaking at about $100 \mathrm{msec}$ followed by a negativity peaking at about $250 \mathrm{msec}$ in mismatch negativity, auditory refractory period, oddball, and passive listening paradigms (e.g., Albrecht et al., 2000; Ponton et al., 2000; Ceponiene, Cheour, \& Näätänen, 1998; Bruneau et al., 1997; Sharma, Kraus, McGee, \& Nicol, 1997; Paetau, Ahonen, Salonen, \& Sams, 1995; Korpilahti \& Lang, 1994; Courchesne, 1990). That is, in these reports, "the polarity of the first wave is opposite" in children as compared with adults (Albrecht 
et al., 2000, p. 2271). These early positivities may be related to the positive component observed here.

We speculate that the observed positivity is not a reversal in polarity of the $\mathrm{N} 1$ in children. Rather, we interpret this finding as an absence of an N1 in children in the present paradigm (see also Ponton et al., 2000; Bruneau et al., 1997; Martin et al., 1988; Daruna \& Rau, 1987). There is growing evidence to suggest that the N1 may be absent in children particularly when stimuli are presented at short interstimulus intervals (Ceponiene et al., 1998; Rojas, Walker, Sheeder, Teale, \& Reite, 1998; Paetau et al., 1995). Probe stimuli were played randomly every $300-800 \mathrm{msec}$ in the present paradigm, in addition to the continuous presentation of the 2 stories. Thus, we hypothesize that the absence of an N1 in the children's waveforms may arise from a saturated auditory system due to the simultaneous presentation of the 2 stories and 2 probe types. We speculate that the complexity and excessive demands of the task-the amount and continuous nature of the auditory input-may be the critical factor in the nonelicitation of the N1. Indeed, that 12 children and 3 adults failed to answer 8 out of the 10 comprehension questions correctly and were excluded from the analyses provides corroborative evidence for the difficulty and demands of the task.

Considering the effects of attention, both linguistic and nonlinguistic probes elicited a greater positivity when played from the attended sound source than when played from the unattended sound source. Thus, the typical effect of an increase in amplitude with attention was observed in children-but on the first clear positivity in the waveform rather than on a nonexistent first negativity; that is, attention in both groups acted to enhance an early component in the waveform (e.g., Woldorff et al., 1993; Woods et al., 1984). Both the anterior, medial distribution of the attention effect and the onset at 100- to 125 -msec were similar for linguistic and nonlinguistic probes. Thus, unlike in adults, there was little evidence that the spatial, linguistic attentional spotlight resulted in differential processing of linguistic and nonlinguistic probe stimuli in children. This may be another indication that there is a narrowing of attentional focus beyond 8 years old (e.g., Berman \& Friedman, 1995).

It is possible that the enhanced positive attention effects observed here in children might be related to the enhanced positivity from 200 to $300 \mathrm{msec}$ for attended second formant tone probes reported in a previous study with adults (Woods et al., 1984). This effect showed a symmetrical distribution and was larger at the vertex than at lateral sites; the present effect has a similar medial and bilateral distribution. However, the previous effect was attributed in part to the "acoustic deviance" of the second formant probes in terms of higher pitch (Woods et al., 1984, p. 774), whereas the present probes were matched on spectral frequency and were not deviant in this or a similar acoustic way.
That the effects of attention were observed on a broad positive wave in children as compared with a welldefined negative peak in adults is consistent with previous ERP research indicating a shift from more broad to more narrow components over developmental time (e.g., Thomas \& Nelson, 1996) and may be related to behavioral findings indicating a long time course for development of attention skills extending into adolescence (e.g., Lane \& Pearson, 1982); indeed, our own behavioral results indicate that adults were better than children at the present task. Previous developmental ERP studies of attention effects have reported no $\mathrm{Nd}_{\mathrm{e}}$ in 6-year-olds (Satterfield et al., 1990); no early Nd effect for CV stimuli, but a typical Nd effect for pure tones in children with mean age of 8.10 years (Berman \& Friedman, 1995); and typical Nd attention effects in adolescents (Berman \& Friedman, 1995; Lovrich \& Stamm, 1983; Loiselle et al., 1980; Zambelli et al., 1977). Across studies, these results suggest a long time course of development across childhood for typical ERP effects of sustained, endogenous attention. To investigate the possibility that only our youngest participants were contributing to the observed positive attention effect, we reviewed the individual data from each child and confirmed that 6-, 7-, and 8-year-olds all evidenced the positivity rather than the typical negativities. (This is consistent with the lack of correlation between age and an ERP difference measure in this group.) It is possible that both the young age of our participants and the relative complexity of our task contributed to our observation of enhanced positivities with attention in children. Further studies with younger and older children should clarify the course of development of the ERP waveform and sustained attention effects, as well as indicating at what point in developmental time ERPs elicited within the present paradigm appear to be mature.

Although other authors have reported a relationship between auditory attention skills and reading ability (e.g., Asbjørnsen \& Bryden, 1998; Taub et al., 1994; Hugdahl \& Andersson, 1987), we found no evidence of a correlation between our standardized behavioral measures of reading and our ERP measure of attention in children, consistent with the results of an auditory ERP study with adolescents (Lovrich \& Stamm, 1983). The present lack of relation may be because of the very selective nature of the group of children: Only those children who scored at least 8 of 10 on the comprehension questions following the ERP task were included in analyses. Behavioral research has shown that the ability to shift attention effectively, as required in the present task, develops across the childhood years (Pearson \& Lane, 1991; Andersson \& Hugdahl, 1987; Hiscock \& Kinsbourne, 1980; Geffen \& Wale, 1979). By including only those children who performed well on our ERP attention task (a necessity to ensure that participants were indeed attending during the experiment), we may have biased our sample to include more developmen- 
tally advanced children or better readers; indeed, scores on the behavioral tests were mostly above average. In restricting the range of participants, significant correlations may have become less likely.

\section{Summary and Conclusion: Children and Adults}

A complex dichotic listening task was successful in indexing the effects of sustained auditory selective spatial attention on ERPs in both children and adults. Interestingly, these attention effects onset at about the same time (100 msec) in children and adults. However, the differences between groups were prominent. The morphology of the auditory ERP waveforms and the polarity of the attention effects in children and adults were markedly different. Only adults evidenced leftlateralized effects, and only adults showed anterior/ posterior distributional differences for linguistic and nonlinguistic probes. In particular, adults evidenced more posterior (cf. Berman \& Friedman, 1995) and longer duration attention effects for linguistic than nonlinguistic probes. The lack of this sort of specialized or distinctive processing in children suggests a longer maturational time course for the processing of linguistic stimuli at least in the context of the present task (see also Berman \& Friedman, 1995). Overall, this pattern of results suggests further refinement of the attentional networks and skills reflected in ERPs elicited by this task, especially with regard to the linguistic probes, beyond the age of 8 years.

\section{METHODS}

\section{Subjects}

The final sample included 22 children (range $=78-107$ months, mean $=92$ months [ 7 years, 9 months], $S D=10$, 14 girls) and 22 adults (range $=228-376$ months, mean $=$ 261 months [21 years, 9 months], $S D=37,11$ women). Participants were right-handed (Oldfield, 1971), monolingual English speakers with no history of neurological or language disorders. All were volunteers paid for their participation. The socioeconomic status of children's families ranged from lower middle to upper class on the Hollingshead Index of Social Position, with a middle-class average. Adults reported normal or corrected-to-normal vision and hearing and all children passed a standard hearing screening (1,2, and $4 \mathrm{kHz}$ under headphones), visual screening for binocular acuity (Kindergarten Snellen chart), and oral-motor screening.

Participants were included in the final analyses only if they met behavioral and electrophysiological criteria. Only participants with a score of at least 8 out of 10 on the posttest comprehension questions related to the attended story (see details below) were included in the analyses to assure that each participant had attended to a minimum of $80 \%$ of the story segments.
In addition, only participants with acceptable ERP data and an adequate number of trials in each condition of interest (see details below) were included in analyses. Nine children were excluded based on failing some aspect of the behavioral screening (e.g., poor hearing, left-handed); 12 children did not answer at least 8 out of 10 comprehension questions correctly and were excluded from the final sample; an additional 36 children had poor electrophysiological data (e.g., not enough trials after eye movement rejection, noisy) and were not included in analyses. An additional 9 adults were excluded because of noisy ERP data (primarily contamination from alpha) and 3 adults were excluded based on incorrect responses to the comprehension questions.

\section{Behavioral Testing}

As part of a wide battery of testing, all children ${ }^{1}$ were given the Word Identification and Word Attack subtests of the Woodcock Reading Mastery Tests-Revised (WRMT, Woodcock, 1987) and the Peabody Picture Vocabulary Test (PPVT, Dunn \& Dunn, 1997). Behavioral and ERP testing occurred in different sessions separated by no more than 35 days.

\section{Event-related Potential Stimuli}

\section{Narratives}

Two stories were digitally recorded (16 bit, $22 \mathrm{kHz}$ ) using an ElectroVoice 1750 microphone connected to a Macintosh computer running a sound editing program (SoundEdit 16, Version 2). The beginning portion of $M y$ Father's Dragon (Gannett, 1948) was read by a female speaker and "The Merry Little Breezes Save the Green Meadows" and a portion of "The Stranger in the Green Forest" from Mother West Wind's Animal Friends (Burgess, 1912) were read by a male speaker; the latter 2 short stories were read consecutively and connected by the phrase "The next day" to form one story. The stories were distinctively different in both style and content and each was read at a slow-normal rate. The stories were edited for outside noises, speech errors, and pauses. Pauses were edited so as not to exceed $1.5 \mathrm{sec}$ to lessen the opportunity for attention switches to the other channel and to lessen the likelihood that the probe stimuli would be heard in the absence of the story. After editing, each story was segmented into 10 sections of the following lengths: 90, 30, 60, 90, 30, 60, 60, 30, 60, and $92 \mathrm{sec}$ (in order). The last segment was slightly longer to end each story at a good point. Each segment of each story was pasted consecutively into the alternate channels of a stereo file. That is, in a stereo file, segment 1 of story 1 was pasted into the right channel and segment 1 of story 2 was pasted into the left channel from 0 to $90 \mathrm{sec}$; segment 2 of story 1 was 
pasted into the left channel and segment 2 of story 2 was pasted into the right channel from 90 to $120 \mathrm{sec}$; and so on. Within each time window, the 2 stories were normalized to control for amplitude differences. Overall, each story switched from one channel to the other at $90,120,180,270,300,360,420,450$, and $510 \mathrm{sec}$, and the entire experiment lasted about $10 \mathrm{~min}$. Stories were played at a comfortable listening level of $65 \mathrm{~dB}$ SPL (Aweighted) on average.

\section{Probe Stimuli}

The linguistic stimulus was a digitized (16 bit, $22 \mathrm{kHz}$ ) token of the syllable $b a$ spoken in a female voice (different from the female storyteller's) with $100 \mathrm{msec}$ duration. The nonlinguistic stimulus was created by editing (CoolEdit) the $b a$ stimulus into 4- to 6-msec segments between zero crossings. Those segments were then randomly reordered to create a sound that was not recognizably speech-like; some segments were also reversed as part of the reordering process. Thus, the nonlinguistic stimulus retained all the primitive acoustic characteristics of the linguistic stimulus; indeed, the frequency spectra of the 2 types of probe stimuli were identical. The nonlinguistic stimulus sounded like a buzz. Each monostimulus could be played from either the left or the right channel; thus, there were 4 probe stimuli: $b a$ right, $b a$ left, buzz right, and buzz left. Probes were presented randomly from each speaker, but across the experiment an equal number $(n=206)$ of linguistic and nonlinguistic probes were presented in the attended and unattended channels.

\section{Visual Fixation Stimuli}

Visual stimuli presented on a monitor directly in front of the participant consisted of $2.5 \times 2.5$-in. colored images of various cartoon characters pointing either to the left or to the right. These images served both as a fixation point and a reminder of which channel to attend.

\section{General Design}

A pair of speakers, one speaker to either side of the seated participant, played the stories and the probe stimuli simultaneously. ${ }^{2}$ At the same time, a monitor in front of the participant displayed the pointing cartoon characters (see Figure 5 for the general design). A trial was as follows: At time 0, a cartoon character pointing either to the left or to the right appeared at the center of the screen. At time $1 \mathrm{sec}$, the stories began to play from the speakers (one story from the left, the other from the right speaker, simultaneously). At time $4 \mathrm{sec}$, the probe stimuli began to play from the speakers and were played randomly from the left and right speaker every 300$800 \mathrm{msec}$. About $2 \mathrm{sec}$ before the end of each story segment, the probe stimuli ceased; then the stories stopped; the cartoon character on the screen was replaced by another character pointing in the other direction; $1 \mathrm{sec}$ later, the stories resumed in the opposite channels.

\section{General Procedure}

The procedures were explained and any questions were addressed, after which adults and parents signed a consent form and children signed an assent form. After
Figure 5. General design of the experiment. The participant is seated in a comfortable chair with speakers equidistant to the left and the right and is instructed to attend to only one narrative (presented in either a woman's or a man's voice). One narrative plays from one speaker at the same time that the other narrative plays from the other speaker; the narratives switch back and forth between the 2 speakers periodically throughout the experiment. A monitor directly in front of the participant shows a cartoon character pointing in one direction; this serves as both a fixation point and a reminder of which side to attend. Simultaneously, ERPs are recorded to linguistic $(/ b a /)$ and nonlinguistic (buzz) probe stimuli superimposed over each narrative.

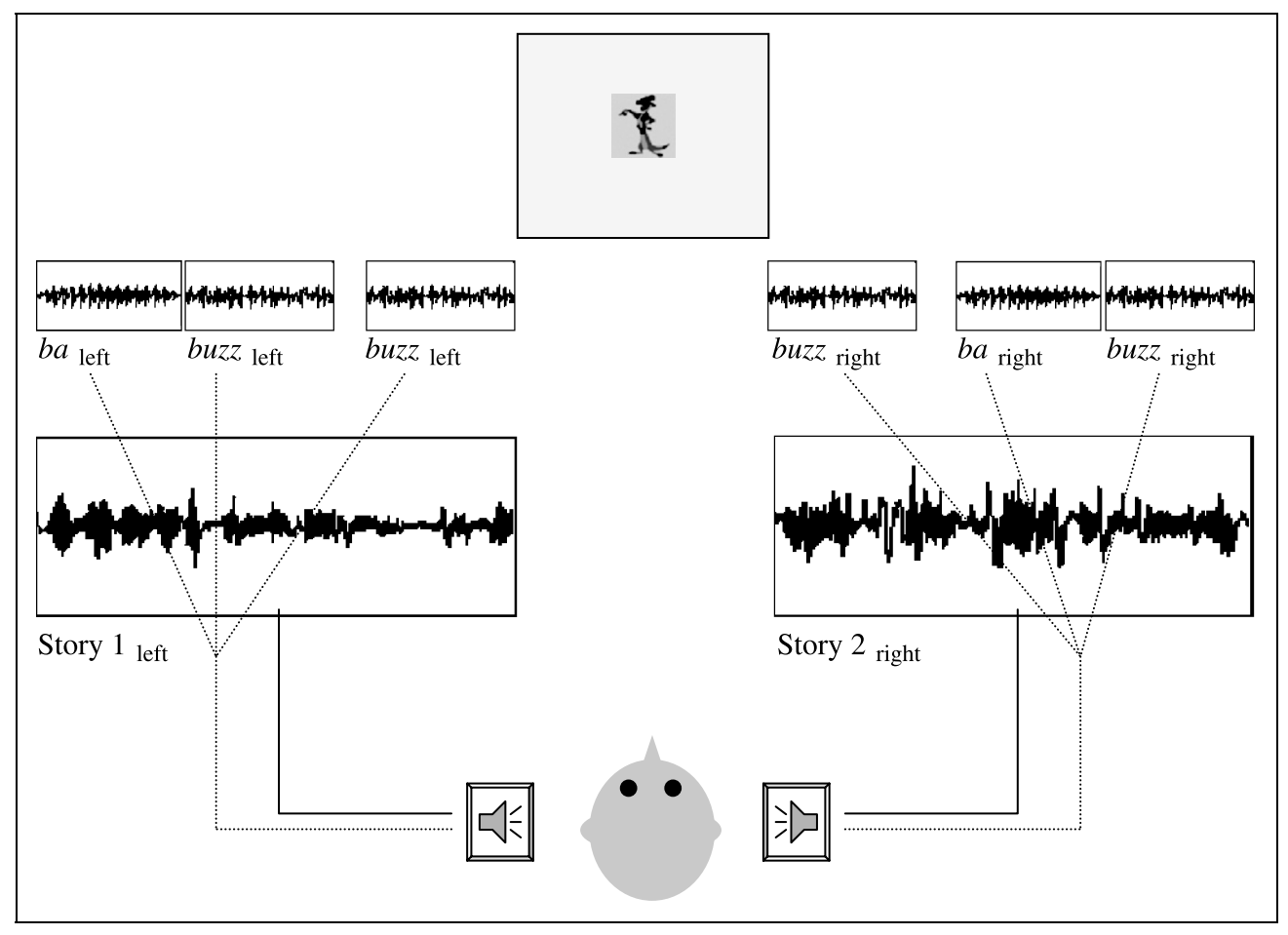


fitting of the electrode cap (see below), participants were seated in a comfortable chair in a sound-attenuating, electrically shielded booth. Small speakers were located on either side of the participant (equidistant), with the monitor $57 \mathrm{in.}$ in front of the participant. A practice session preceded the actual test session and instructions were given as part of the practice. Attendance to the Mother West Wind story (male voice, left side start) or the My Father's Dragon story (female voice, right side start) was counterbalanced across all participants (children: 11 left start and 11 right start; adults: 10 left start and 12 right start). The voice that started the practice session corresponded to the attended voice in the actual test session. During the practice, each element of the experiment was introduced singly (refer to the Appendix for further details regarding the practice session).

Following the practice session, any questions or concerns were addressed before the start of the experiment, the participant was again instructed not to move or lean from side to side (monitored continuously by a closedcircuit camera and by an experimenter sitting next to the children) and to listen carefully to be able to answer the questions at the end and was reminded which side to listen to first (by both a verbal label and a manual point). Subsequently, the experiment was begun with a cartoon character pointing to the indicated side and the start of the stories.

At the end of the experiment, participants were read 10 simple yes-or-no questions about salient aspects of the story to which they had listened (indexing the main idea of each segment) and 3 simple yes-or-no questions about salient aspects of the story to which they had not been attending. Questions from the 2 stories were presented intermixed and responses were recorded manually.

\section{Electroencephalogram/Event-related Potential Recording and Analysis}

Electroencephalogram (EEG) was recorded from 29 tin electrodes mounted in an elastic cap (Electro-Cap International). These included 3 midline sites $(\mathrm{Fz}, \mathrm{Cz}$, and $\mathrm{Pz}$ ) and 13 pairs of lateral sites (FP1/2, F7/8, FT7/8, F3/4, FC5/ 6, C3/4, C5/6, T3/4, CT5/6, P3/4, T5/6, TO1/2, and O1/2; refer to Figure 6). Electrodes were also placed beneath the lower right eye and at the outer canthi of the left and right eyes to monitor eye movements (electrooculogram); in addition, recordings from FP $1 / 2$ were used to reject trials that were contaminated by eyeblink artifacts. Activity at the left mastoid was recorded during the experiment, but all on-line recordings were referenced to the right mastoid; recordings were re-referenced to averaged mastoids in the final data averaging. Eye electrode impedances were maintained below $10 \mathrm{k} \Omega$, mastoid electrodes below $2 \mathrm{k} \Omega$, and scalp electrodes below $3 \mathrm{k} \Omega$.

The EEG was amplified with Grass 7P511 amplifiers ( $-3 \mathrm{~dB}$ cutoff, bandpass 0.01 to $100 \mathrm{~Hz}$ ) and digitized on-line (sampling rate $4 \mathrm{msec}$ ). Off-line, separate ERPs to the 4 types of probe stimuli (linguistic attended, linguistic unattended, nonlinguistic attended, nonlinguistic unattended) were averaged for each subject at each electrode site over a 500-msec epoch, using a 100-msec prestimulus-onset baseline. Trials contaminated by eye movements, muscular activity, or electrical noise were not included in analyses. Standard artifact rejection parameters were initially employed, including routines to identify reversals of polarity across the electrode below the eye and FP1 (to identify blinks and vertical eye movements), amplitude fluctuations at the horizontal eye channels (to identify lateral eye movements), amplifier blocking, and high amplitude activity (to identify noise, movement); data were subsequently carefully analyzed on an individual basis for stricter artifact rejection as necessary. A minimum of 30 artifact-free trials in each of the 4 main conditions was imposed. The average number of useable trials in the attended linguistic condition was $140.0 \pm 51.7$ for adults and 94.5 \pm 39.0 for children, and the average number of useable trials in the unattended linguistic condition was $138.3 \pm 53.1$ for adults and $97.7 \pm 38.2$ for children. The average number of useable trials in the attended nonlinguistic condition was $138.2 \pm 53.3$ for adults and $95.7 \pm 36.0$ for children, and the average number of useable trials in the unattended nonlinguistic condition was $140.0 \pm 52.5$ for adults and $95.6 \pm 35.0$ for children.

\section{Statistical Analyses}

To fully characterize the early components of the ERP waveform in adults, local peak amplitude and latency were measured in 3 time windows: positive peak 50150 msec (P1), negative peak 100-200 msec (N1, latency only), and positive peak 200-400 msec (P2). A peakto-peak amplitude measurement was taken between P1 and N1 to more accurately describe the distribution of the N1. ${ }^{3}$ Peak measures were subjected to a 6-way mixed-design repeated measures analysis of variance (ANOVA) as described below. As data from individual children did not evidence peaks clearly defined enough to permit this type of measurement, analyses of children's ERPs were limited to the mean amplitude measures described below.

To quantify the effect of attention in children and adults, the mean amplitude of ERPs to attended and unattended probes was measured within the 100- to 250-msec time window in children and within the 100to 175 - and 100- to 250-msec epochs in adults (as well as within the 175 - to 250 -msec epoch for comparative purposes). Six-way mixed-design repeated ANOVAs were performed on the mean amplitude data for each age group. Within-subject factors included attention (2 possible levels: attended, unattended), probe type (2 possible levels: linguistic, nonlinguistic), hemisphere (2 possible levels: left, right), laterality ( 2 possible levels: lateral, medial), and anterior/posterior ( 6 possible levels: 
frontal, fronto-temporal, temporal, central, parietal, occipital; refer to Figure 6). The single between-subjects factor was start side (2 possible levels: left start, right start). Because there were no significant effects or interactions involving start side and attention in omnibus analyses, this factor was removed from subsequent analyses of mean and peak data as reported. The Greenhouse-Geisser correction was applied to all within-subjects measures with more than 2 levels.

In addition, within each group, analyses by consecutive 25 -msec epochs from 0 to $300 \mathrm{msec}$ poststimulus onset were conducted with mean amplitude data to more precisely temporally locate the onset of the attention effects; significant results involving attention across 3 consecutive epochs were considered an indication of onset in the earliest epoch.

Further, to directly compare the distributions of the attention effects observed in children and adults, mean amplitude data were normalized as follows: For each

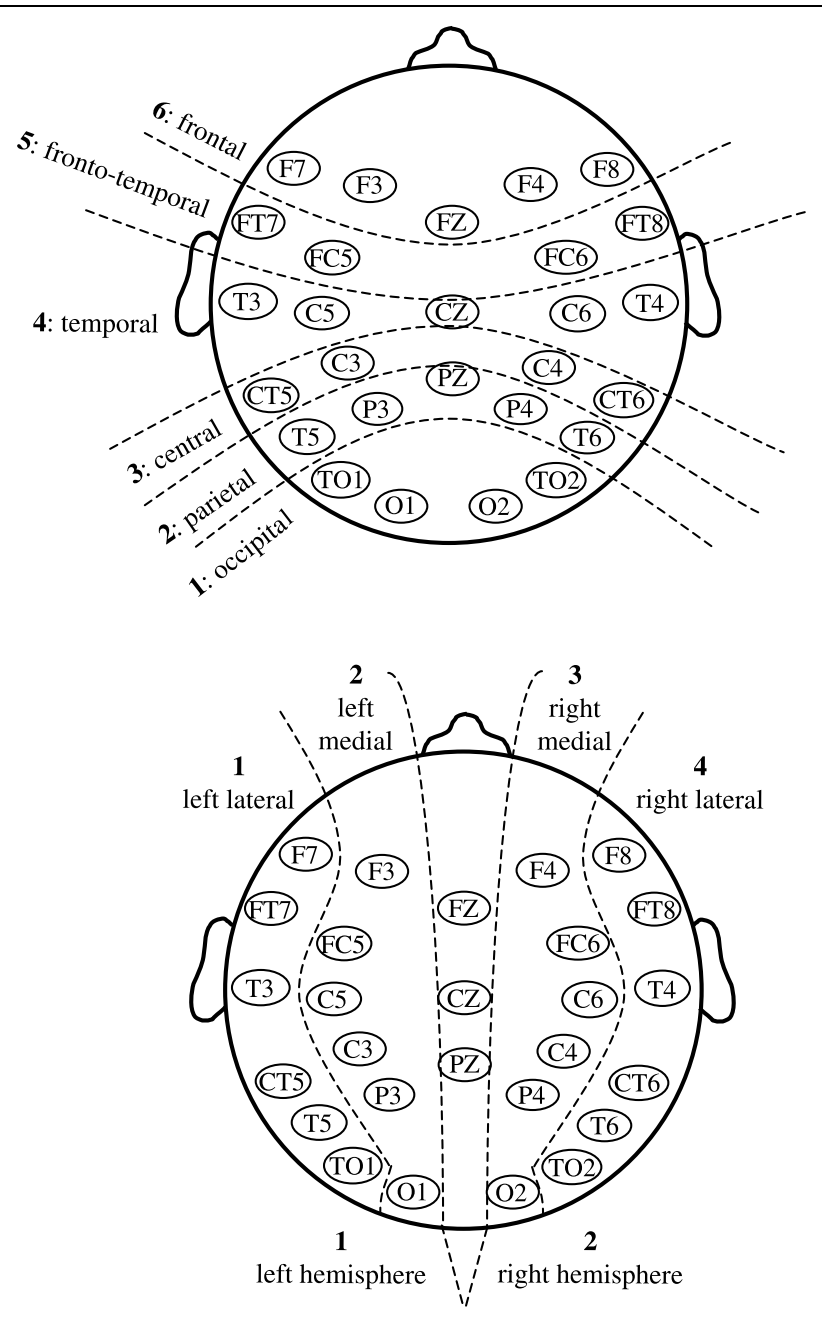

Figure 6. Schematic representation of the electrode montage and the factors used in analyses. At the top, 6 levels of the anterior/posterior factor are illustrated. At the bottom, 2 levels of the lateral/medial factor and 2 levels of the hemisphere factor are indicated. group and probe type, the grand mean and standard deviation across electrode site and subject were calculated. Then, for each subject at each site, the grand mean was subtracted from the mean amplitude and divided by the standard deviation.

Finally, for the group of children, Pearson's correlations were calculated to investigate relationships among our behavioral and electrophysiological measures; specifically, between the behavioral measures of reading and the ERP attention effect.

\section{APPENDIX: PRACTICE SESSION}

First practice segment, attend to male voice condition: Male voice from left speaker saying, "In this experiment, your job is to listen to a story. I will be telling the story, so you will be listening to my voice. You need to listen to the story very carefully, because we will ask you some questions about the story at the end. While you listen to the story, you must sit as still as you can and look straight ahead, watching the screen in front of you. On the screen, you can see a cartoon character pointing one way or the other. Right now, Woody is pointing to the left, the side you are hearing my voice come from. Every once in a while, a different character will appear on the screen, pointing in the other direction [Peter Pan appears on the screen, pointing to the right], and my voice will change to the other side..." Second practice segment, male voice from the right speaker: ". . like this. So now my voice is coming from the right side, and Peter Pan is pointing to that side. It is very important that you look straight ahead at the screen and watch the cartoon characters while you are listening to the story, because they will tell you which side to listen to. That way, you can follow my voice as I tell the story from one side to the other, and you won't miss any of the story." Third practice segment, male voice from the left speaker: "Did you see the cartoon character change and point in the other direction? Did you follow my voice to the other side? Now my voice is coming from the left and Puumba is pointing in that direction. When you can hear only my voice, it is not too hard to pay attention to what I'm saying, but during the experiment, there will be another voice telling another story at the same time that I am telling my story. It will sound something like this [add female voice from right speaker]. So, while I am talking, another person will also be talking at the same time. Remember that your job is to listen to my voice telling the story. You can just ignore the other voice; you don't need to pay any attention to the other voice. You need to listen to my voice so that you don't miss part of the story. Remember to ignore the other voice and follow my voice from side to side as I tell the story." Final practice segment, female voice from the left speaker and male voice from the right speaker, saying, "Did you see the cartoon character change and point in the other direction? Are you ignoring the other voice? 
Good, you followed my voice back to the other side, where Bianca the mouse is pointing, and you are paying attention to just my voice. Sometimes during the experiment, there will also be other sounds; your job is just to listen to my voice telling the story. The other sounds will sound like this [introduce probe stimuli from left and right speakers]. You need to concentrate very hard and pay attention to my voice telling the story, even if there are other sounds at the same time. So your job is to listen to my voice telling the story and follow the story as it changes from one side to the other; the cartoon characters will help you know which side to listen to by pointing in that direction. Listen carefully to the story, because we will ask you some questions about the story at the end. Are you ready to hear the story now? The name of the story is Mother West Wind's Animal Friends, and it will start on the other side in just a minute."

\section{Acknowledgments}

This research was supported by NIH grants DC00481 to H.J.N. (NIDCD), HD08598 to D.C. (NICHD), and DC0529101 to L.D.S (NIDCD). We thank the children and parents, as well as the college students, who participated in this study. We also thank Mark Dow for his excellent storytelling voice, his patience, and his technical assistance, Ray Vukcevich and Paul Compton for their programming and technical expertise, and Wendy Skendzel, Libbey White, Cheryl Capek, Jennifer Woods, and Courtney Stevens for their help in running subjects in the ERP paradigm. We also thank the students in the Communication Disorders and Sciences Department of the University of Oregon, including Kim Stahlnecker, Rebecca Andes, Jill Duthie, Suzanne Israels, Christine Hinshon, Kris Marion, Karen Bohlin, Amy Letts, and especially Jessica Fanning, who conducted the behavioral testing under the supervision of Dr. Marilyn Nippold. Finally, we thank the anonymous reviewers for their helpful comments and suggestions.

Reprint requests should be sent to Donna Coch, Department of Education, Dartmouth College, 203 Raven House, Hanover, NH 03755, or via e-mail: donna.j.coch@dartmouth.edu.

\section{Notes}

1. With the exception of one 7-year-old boy.

2. Stimuli were presented over speakers because using headphones in combination with the electrode cap with children is difficult and because using free-field auditory stimuli seemed a more ecologically valid measure.

3. Because of the nature of the waveforms, the mean amplitude measure of $\mathrm{N} 1$ did not accurately represent the distribution of the component (e.g., refer to Figure 1A, wherein $\mathrm{N} 1$ appears to be larger at lateral and posterior sites because the overall waveform tends to be more negative at these sites). The attention effects are best revealed by the mean amplitude measures, but the distribution of the component is best described with the peak-to-peak measure; results are reported accordingly.

\section{REFERENCES}

Albrecht, R., Suchodoletz, W. v., \& Uwer, R. (2000). The development of auditory evoked dipole source activity from childhood to adulthood. Clinical Neurophysiology, 111, 2268-2276.

Alho, K., Medvedev, S. V., Pakhomov, S. V., Roudas, M. S., Tervaniemi, M., Reinikainen, K., Zeffiro, T., \& Näätänen, R. (1999). Selective tuning of the left and right auditory cortices during spatially directed attention. Cognitive Brain Research, 7, 335-341.

Andersson, B., \& Hugdahl, K. (1987). Effects of sex, age, and forced attention on dichotic listening in children: A longitudinal study. Developmental Neuropsychology, 3, 191-206.

Asbjørnsen, A. E., \& Bryden, M. P. (1998). Auditory attentional shifts in reading-disabled students: Quantification of attentional effectiveness by the Attentional Shift Index. Neuropsychologia, 36, 143-148.

Berman, S., \& Friedman, D. (1995). The development of selective auditory attention as reflected by event-related brain potentials. Journal of Experimental Child Psychology, 59, 1-31.

Bruneau, N., Roux, S., Guérin, P., Barthélémy, C., \& Lelord, G. (1997). Temporal prominence of auditory evoked potentials (N1 wave) in 4-8-year-old children. Psychophysiology, 34, 32-38.

Burgess, T. W. (1912). Mother West Wind's animal friends. New York: Grosset \& Dunlap.

Ceponiene, R., Cheour, M., \& Näätänen, R. (1998). Interstimulus interval and auditory event-related potentials in children: Evidence for multiple generators. Electroencephalography and Clinical Neurophysiology, 108, 345-354.

Coch, D., Grossi, G., Coffey-Corina, S., Holcomb, P. J., \& Neville, H. J. (2002). A developmental investigation of ERP auditory rhyming effects. Developmental Science, 5, 467-489.

Courchesne, E. (1990). Chronology of postnatal human brain development: Event-related potentials, positron emission tomography, myelinogenesis, and synaptogenesis studies. In J. R. Rohrbaugh, R. Parasuraman, \& R. Johnson (Eds.), Event-related brain potentials: Basic issues and applications (pp. 210-241). New York: Oxford University Press.

Daruna, J. H., \& Rau, A. E. (1987). Development of the late components of auditory brain potentials from early childhood to adulthood. In R. Johnson, J. W. Rohrbaugh, \& R. Parasuraman (Eds.), Current trends in event-related potential research. EEG Supplement 40 (pp. 590-595). Amsterdam: Elsevier.

Davis, E. P., Bruce, J., Snyder, K., \& Nelson, C. A. (2003). The $\mathrm{x}$-trials: Neural correlates of an inhibitory control task in children and adults. Journal of Cognitive Neuroscience, 15, 432-443.

Dehaene-Lambertz, G., Dehaene, S., \& Hertz-Pannier, L. (2002). Functional neuroimaging of speech perception in infants. Science, 298, 2013-2015.

Dickstein, P. W., \& Tallal, P. (1987). Attentional capabilities of reading-impaired children during dichotic presentation of phonetic and complex nonphonetic sounds. Cortex, 23, 237-249.

Doyle, A.-B. (1973). Listening to distraction: A developmental study of selective attention. Journal of Experimental Child Psychology, 15, 100-115.

Dunn, L. M., \& Dunn, L. M. (1997). Peabody Picture Vocabulary Test (3rd ed.). Circle Pines, MN: American Guidance Service.

Elliott, L. L. (1979). Performance of children aged 9 to 17 years on a test of speech intelligibility in noise using sentence material with controlled word predictability. Journal of the Acoustical Society of America, 66, 651-653. 
Fuchigami, T., Okubo, O., Fujita, Y., Okuni, M., Noguchi, Y., \& Yamada, T. (1993). Auditory event-related potentials and reaction time in children: Evaluation of cognitive development. Developmental Medicine and Child Neurology, 35, 230-237.

Gannett, R. S. (19) $\overline{48) . ~ M y ~ f a t b e r ' s ~ d r a g o n . ~ N e w ~ Y o r k: ~ R a n d o m ~}$ House.

Geffen, G., \& Sexton, M. A. (1978). The development of auditory strategies of attention. Developmental Psychology, 14, 11-17.

Geffen, G., \& Wale, J. (1979). Development of selective listening and hemispheric asymmetry. Developmental Psychology, 15, 138-146.

Goodin, D. S., Squires, K. C., Henderson, B. H., \& Starr, A. (1978). Age-related variations in evoked potentials to auditory stimuli in normal human subjects.

Electroencephalography and Clinical Neurophysiology, 44, 447-458.

Hansen, J. C., \& Hillyard, S. A. (1980). Endogenous brain potentials associated with selective auditory attention. Electroencephalography and Clinical Neurophysiology, 49, 277-290.

Hansen, J. C., Dickstein, P. W., Berka, C., \& Hillyard, S. A. (1983). Event-related potentials during selective attention to speech sounds. Biological Psychology, 16, 211-224.

Hillyard, S. A., \& Picton, T. W. (1987). Electrophysiology of cognition: Selective attention. In F. Plum (Ed.), Handbook of physiology section I: The nervous system. Higher functions of the brain, Part II (pp. 534-546). Bethesda, MD: American Physiological Society.

Hillyard, S. A., Hink, R. F., Schwent, V. L., \& Picton, T. W. (1973). Electrical signs of selective attention in the human brain. Science, 182, 177-180.

Hink, R. F., \& Hillyard, S. A. (1976). Auditory evoked potentials during selective listening to dichotic speech messages. Perception and Psychophysics, 29, 236-242.

Hink, R. F., Hillyard, S. A., \& Benson, P. J. (1978). Event-related brain potentials and selective auditory attention to acoustic and phonetic cues. Biological Psychology, 6, 1-16.

Hink, R. F., van Voorhis, S. T., Hillyard, S. A., \& Smith, T. S. (1977). The division of attention and the human auditory evoked potential. Neuropsychologia, 15, 597-605.

Hiscock, M., \& Kinsbourne, M. (1980). Asymmetries of selective listening and attention switching in children. Developmental Psychology, 16, 70-82.

Hugdahl, K., \& Andersson, B. (1987). Dichotic listening and reading acquisition in children: A one-year follow-up. Journal of Clinical and Experimental Neuropsychology, 9, 631-649.

Hugdahl, K., Brønnick, K., Kyllingsbæk, S., Law, I., Gade, A., \& Paulson, O. B. (1999). Brain activation during dichotic presentations of consonant-vowel and musical instrument stimuli: A ${ }^{15}$ O-PET study. Neuropsychologia, 37, 431-440.

Hugdahl, K., Law, I., Kyllingsbæk, S., Brønnick, K., Gade, A., \& Paulson, O. B. (2000). Effects of attention on dichotic listening: An ${ }^{15} \mathrm{O}-\mathrm{PET}$ study. Human Brain Mapping, 10 , 87-97.

Korpilahti, P., \& Lang, H. A. (1994). Auditory ERP components and mismatch negativity in dysphasic children.

Electroencephalography and Clinical Neurophysiology, 91, 256-264.

Lane, D. M., \& Pearson, D. A. (1982). The development of selective attention. Merrill-Palmer Quarterly, 28, 317-337.

Loiselle, D. L., Stamm, J. S., Maitinsky, S., \& Whipple, S. C. (1980). Evoked potential and behavioral signs of attentive dysfunctions in hyperactive boys. Psychophysiology, 17, 193-201.
Lovrich, D., \& Stamm, J. S. (1983). Event-related potential and behavioral correlates of attention in reading retardation. Journal of Clinical Neuropsychology, 5, 13-37.

Luck, S. J. (1998). Neurophysiology of selective attention. In H. Pashler (Ed.), Attention (pp. 257-295). East Sussex, UK: Psychology Press.

Maccoby, E. E., \& Konrad, K. W. (1966). Age trends in selective listening. Journal of Experimental Child Psychology, 3, 113-122.

Martin, L., Barajas, J. J., Fernandez, R., \& Torres, E. (1988). Auditory event-related potentials in well-characterized groups of children. Electroencephalography and Clinical Neurophysiology, 71, 375-381.

Mills, D. L., Coffey-Corina, S. A., \& Neville, H. J. (1993). Language acquisition and cerebral specialization in 20-month-old infants. Journal of Cognitive Neuroscience, 5, 317-334.

Molfese, D. L., \& Molfese, V. J. (1988). Right-hemisphere responses from preschool children to temporal cues to speech and nonspeech materials: Electrophysiological correlates. Brain and Language, 33, 245-259.

Molfese, D. L., Freeman, R. B., \& Palermo, D. S. (1975). The ontogeny of brain lateralization for speech and nonspeech stimuli. Brain and Language, 2, 356-368.

Näätänen, R. (1979). Early selective attention effects on the evoked potential: A critical review and reinterpretation. Biological Psychology, 8, 81-136.

Näätänen, R. (1982). Processing negativity: An evoked-potential reflection of selective attention. Psychological Bulletin, 92, 605-640.

Näätänen, R., \& Picton, T. (1987). The N1 wave of the human electric and magnetic response to sound: A review and an analysis of the component structure. Psychophysiology, 24, 375-425.

Neville, H. J., \& Bavelier, D. (2000). Specificity and plasticity in neurocognitive development in humans. In M. S. Gazzaniga (Ed.), The new cognitive neurosciences (2nd ed., pp. 83-98). Cambridge: MIT Press.

Oades, R. D., Dittmann-Balcar, A., \& Zerbin, D. (1997). Development and topography of auditory event-related potentials (ERPs): Mismatch and processing negativity in individuals 8-22 years of age. Psychophysiology, 34, 677-693.

Oldfield, R. C. (1971). The assessment and analysis of handedness: The Edinburgh Inventory. Neuropsychologia, 9, 97-113.

Paetau, R., Ahonen, A., Salonen, O., \& Sams, M. (1995). Auditory evoked magnetic fields to tones and pseudowords in healthy children and adults. Journal of Clinical Neurophysiology, 12, 177-185.

Pang, E. W., \& Taylor, M. J. (2000). Tracking the development of the N1 from age 3 to adulthood: An examination of speech and non-speech stimuli. Clinical Neurophysiology, 111, 388-397.

Pearson, D. A., \& Lane, D. M. (1991). Auditory attention switching: A developmental study. Journal of Experimental Child Psychology, 51, 320-334.

Peña, M., Maki, A., Kovacic, D., Dehaene-Lambertz, G., Koizumi, H., Bouquet, F., \& Mehler, J. (2003). Sounds and silence: An optical topography study of language recognition at birth. Proceedings of the National Academy of Sciences, U.S.A., 100, 11702-11705.

Petkov, C. I., Kang, X., Alho, K., Bertrand, O., Yund, E. W., \& Woods, D. L. (2004). Attentional modulation of human auditory cortex. Nature Neuroscience, 7, 658-663.

Poldrack, R. A., Temple, E., Protopapas, A., Nagarajan, S., Tallal, P., Merzenich, M., \& Gabrieli, J. D. E. (2001). Relations between the neural bases of dynamic auditory processing 
and phonological processing: Evidence from fMRI. Journal of Cognitive Neuroscience, 13, 687-697.

Ponton, C. W., Eggermont, J. J., Kwong, B., \& Don, M. (2000). Maturation of human central auditory system activity: Evidence from multi-channel evoked potentials. Clinical Neurophsyiology, 111, 22-236.

Ridderinkhof, K. R., \& van der Stelt, O. (2000). Attention and selection in the growing child: Views derived from developmental psychophysiology. Biological Psychology, 54, 55-106.

Rojas, D. C., Walker, J. R., Sheeder, J. L., Teale, P. D., \& Reite, M. L. (1998). Developmental changes in refractoriness of the neuromagnetic M100 in children. NeuroReport, 9, 1543-1547.

Rueda, M. R., Fan, J., McCandliss, B. D., Halparin, J. D., Gruber, D. B., Lercari, L. P., \& Posner, M. I. (2004). Development of attentional networks in childhood. Neuropsychologia, 42, 1029-1040.

Sanders, L. D., Spezio, M. L., Dow, M., Weaver, J., Baufman, D. J., Woods, D. L., \& Neville, H. J. (2001). Attention to auditory location and pitch: A behavioral, ERP, and fMRI study [abstract]. Annual Meeting of the Cognitive Neuroscience Society. New York: Cognitive Neuroscience Society.

Satterfield, J. H., Schell, A. M., \& Nicholas, T. (1994). Preferential neural processing of attended stimuli in attention-deficit hyperactivity disorder and normal boys. Psychophysiology, 31, 1-10.

Satterfield, J. H., Schell, A. M., Nicholas, T., \& Backs, R. W. (1988). Topographic study of auditory event-related potentials in normal boys and boys with attention deficit disorder with hyperactivity. Psychophysiology, 25, 591-606.

Satterfield, J. H., Schell, A. M., Nicholas, T. W., Satterfield, B. T., \& Freese, T. E. (1990). Ontogeny of selective attention effects on event-related potentials in attention-deficit hyperactivity disorder and normal boys. Biological Psychiatry, 28, 879-903.

Segalowitz, S. J., \& Cohen, H. (1989). Right hemisphere EEG sensitivity to speech. Brain and Language, 37, 220-231.

Sexton, M. A., \& Geffen, G. (1979). Development of three strategies of attention in dichotic monitoring. Developmental Psychology, 15, 299-310.

Sharma, A., Kraus, N., McGee, T. J., \& Nicol, T. G. (1997). Developmental changes in P1 and N1 central auditory responses elicited by consonant-vowel syllables.

Electroencephalography and Clinical Neurophysiology, 104, 540-545.

Shtyrov, Y., Kujala, T., Palva, S., Ilmoniemi, R. J., \& Näätänen, R. (2000). Discrimination of speech and complex nonspeech sounds of different temporal structure in the left and right cerebral hemispheres. Neuroimage, 12, 657-663.

Simos, P. G., Molfese, D., \& Brenden, R. A. (1997). Behavioral and electrophysiological indices of voicing-cue discrimination: Laterality patterns and development. Brain and Language, 57, 122-150.

Szymanski, M. D., Yund, E. W., \& Woods, D. L. (1999). Human brain specialization for phonetic attention. NeuroReport, 10, 1605-1608.

Takeshita, K., Nagamine, T., Thuy, D. H. D., Satow, T., Matsuhashi, M., Yamamoto, J., Takayama, M., Fujiwara, N., \& Shibasaki, H. (2002). Maturational change of parallel auditory processing in school-aged children revealed by simultaneous recording of magnetic and electric cortical responses. Clinical Neurophysiology, 113, 1470-1484.
Taub, C. F., Fine, E., \& Cherry, R. S. (1994). Finding a link between selective auditory attention and reading problems in young children: A preliminary investigation. Perceptual and Motor Skills, 78, 1153-1154.

Teder, W., Kujala, T., \& Näätänen, R. (1993). Selection of speech messages in free-field listening. NeuroReport, 5, 307-309.

Teder-Sälejärvi, W. A., Hillyard, S. A., Röder, B., \& Neville, H. J. (1999). Spatial attention to central and peripheral auditory stimuli as indexed by event-related potentials. Cognitive Brain Research, 8, 213-227.

Thomas, K. M., \& Nelson, C. A. (1996). Age-related changes in the electrophysiological response to visual stimulus novelty: A topographical approach. Electroencephalography and Clinical Neurophysiology, 98, 294-308.

Tonnquist-Uhlén, I., Borg, E., \& Spens, K. E. (1995). Topography of auditory evoked long-latency potentials in normal children, with particular reference to the N1 component. Electroencephalography and Clinical Neurophysiology, 95, 34-41.

Trejo, L., Ryan-Jones, D. L., \& Kramer, A. F. (1995). Attentional modulation of the mismatch negativity elicited by frequency differences between binaurally presented tone bursts. Psychophysiology, 32, 319-328.

Woldorff, M., Hansen, J. C., \& Hillyard, S. A. (1987). Evidence for effects of selective attention in the mid-latency range of the human auditory event-related potential. In R. Johnson, J. W. Rohrbaugh, \& R. Parasuraman (Eds.), Current trends in event-related potential research. EEG Supplement 40 (pp. 146-154). Amsterdam: Elsevier.

Woldorff, M. G., Gallen, C. C., Hampson, S. A., Hillyard, S. A., Pantev, C., Sobel, D., \& Bloom, F. E. (1993). Modulation of early sensory processing in human auditory cortex during auditory selective attention. Proceedings of the National Academy of Sciences, U.S.A., 90, 8722-8726.

Woldorff, M. G., \& Hillyard, S. A. (1991). Modulation of early auditory processing during selective listening to rapidly presented tones. Electroencephalography and Clinical Neurophysiology, 79, 170-191.

Woodcock, R. W. (1987). The Woodcock Reading Mastery Tests-Revised. Circle Pines, MN: American Guidance Service.

Woods, D. L. (1990). The physiological basis of selective attention: Implications of event-related potential studies. In J. W. Rohrbaugh, R. Parasuraman, \& J. R. Johnson (Eds.), Event-related potentials: Basic issues and applications (pp. 178-209). New York: Oxford University Press.

Woods, D. L., \& Alain, C. (1993). Feature processing during high-rate auditory selective attention. Perception and Psychophysics, 53, 391-402.

Woods, D. L., Alho, K., \& Algazi, A. (1991). Brain potential signs of feature processing during auditory selective attention. NeuroReport, 2, 189-192.

Woods, D. L., Hillyard, S. A., \& Hansen, J. C. (1984). Event-related brain potentials reveal similar attentional mechanisms during selective listening and shadowing. Journal of Experimental Psychology: Human Perception and Performance, 10, 761-777.

Zambelli, A. J., Stamm, J. S., Maitinsky, S., \& Loiselle, D. L. (1977). Auditory evoked potentials and selective auditory attention in formerly hyperactive adolescent boys. American Journal of Psychiatry, 134, 742-747.

Zatorre, R. J., Evans, A. C., Meyer, E., \& Gjedde, A. (1992). Lateralization of phonetic and pitch discrimination in speech processing. Science, 256, 846-849.

Zukier, H., \& Hagen, J. W. (1978). The development of selective attention under distracting conditions. Child Development, 49, 870-873. 